\title{
Active Power and DC Voltage Coordinative Control for Cascaded DC-AC Converter with Bidirectional Power Application
}

\author{
Yanjun Tian, Student Member, IEEE, Zhe Chen, Senior Member, IEEE, Fujin Deng, Member, IEEE, \\ Xiaofeng Sun, Member, IEEE, Y Yanting Hu, Senior Member, IEEE
}

\begin{abstract}
Two stage cascaded converters are widely used in DC/AC hybrid systems to achieve the bidirectional power transmission. The topology of dual active bridge cascaded with inverter (DABCI) is commonly used in this application. This paper proposes a coordinative control method for DABCI and it's able to reduce the DC-link voltage fluctuation between the DAB and inverter, then reduce the stress on the switching devices, as well as improve the system dynamic performance. In the proposed control method, the DAB and inverter are coordinated to control the DClink voltage and the power, and this responsibility sharing control can effectively suppress the impact of the power variation on the DC-link voltage, without sacrificing stability. The proposed control method is also effective for DABCI in unidirectional power transmission. The effectiveness of the propose control has been validated by both simulations and experiments.
\end{abstract}

Index Terms-Bidirectional control, cascaded converters, coordinative control, DC-link voltage control

\section{INTRODUCTION}

$\mathrm{W}$ HIT the increasing of Distributed Generations (DG), more and more renewable energy based generation units are integrated into the power systems, and they are in the form of AC or DC sources, such as the wind turbines, photovoltaic panels, biofuel and biomass generations. Forming a local DC or AC active distribution network is an efficient way to integrate these DGs to support the local loads, as well as feed the utility grid[1-4]. The inter-connection between the DC and AC active networks could become necessary, and a high effective interface converter would be the key issue to realize this connection.

The interface converter between AC and DC systems normally fulfills the following requirements [5]: (1) Voltage buck-boost capability. (2) Bidirectional power control. (3) Galvanic isolation. (4) High power density and high efficiency. Several bidirectional buck-boost or boost inverters have been presented. Reference [6] offered a three phase single stage distributed power inverter, and it has the capability of voltage boost, with less switching devices, but cannot realize the galvanic isolation. Reference [7] introduced a new topology of a boost inverter, which needs more switches, especially for three-phase applications. Z-source inverter can achieve boost dc/ac inversion and buck ac-dc rectification [8], but its efficiency is not high, and it could be difficult for high power applications. Reference [9] offered a boost inverter for fuel cell applications, but it can not be used in high power three-phase applications. The dual-active-bridge (DAB) has a number of significant advantages: The high-frequency transformer can realize galvanic isolation and high-power density; the symmetric topology can achieve bidirectional power flow; $\mathrm{H}$ bridges with a transformer can easily operate in a zero voltage switching mode [10-15]. So the DAB cascaded with inverter (DABCI) is attractive for the interface converter between AC

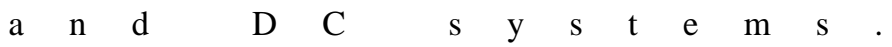
Studies about the hybrid AC/DC systems are presented [4, 16-21].References [17] and [18] offered a DC-link capacitor minimized control method for two stage cascaded interface converter, and it uses one converter to control input DC voltage, and the other controls the DC-link voltage. Reference [19] introduced an unbalance power control method for multiterminal solid state transformer, and it used the topology of paralleled DABs connected to one inverter. It focused on the power distribution and power sharing, and did not analyze the bidirectional control or dynamic response. For the cascaded converter, conventional control methods use one sub-converter to control DC-link voltage, and the other controls the power output. When power flow is reversed, sub-converters swap the control objectives with each other [20,21 32], but the function swapping increases the complexity and reduces the system redundancy. Different transient behaviors between the DAB and inverter cause transient power unbalance, either in bidirectional or unidirectional applications. The power unbalance results in the variation of DC-link voltage, and the potential over voltage increases the stress on the semiconductor devices and causes grid power quality problems.

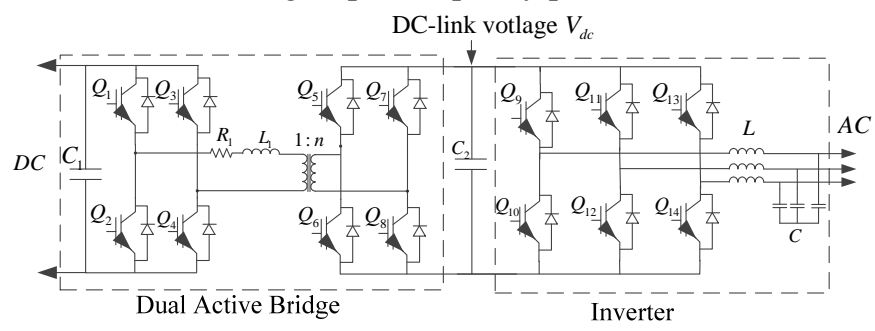

Fig. 1 Topology of interface converter DABCI

In this paper, an active power and DC-link voltage 
coordinative control method is proposed for the DABCI. The proposed control method shares DC-link voltage control and power control between the $\mathrm{DAB}$ and inverter. Without swapping control functions or sacrificing the stability, the proposed control can effectively improve the dynamic behavior of the DABCI with better DC-link voltage maintenance and power control. With better controlled DC-link voltage, the stress on the switching devices is reduced, which is significant to prolong system devices' life time.

The paper is organized as follows. The modeling and conventional control of DABCI are analyzed in Section II. Section III introduces the proposed coordinative control with detail analysis. Sections IV presents the simulation and experiment results, and Section $\mathrm{V}$ gives the conclusions.

\section{TRAditional CONTROL OF THE CASCADED DAB AND INVERTER}

Fig. 1 shows the topology of DABCI, DAB cascaded with inverter. $R_{1}$ and $L_{1}$ are respectively the parasitic resistance and leakage inductance of the transformer.

In Fig. 1, the DAB and inverter are recognized as the subconverters. The conventional control uses one sub-converter to maintain the DC-link voltage $\mathrm{V}_{\mathrm{dc}}$ (on capacitor $\mathrm{C} 2$ ), and the other one controls the power output. For example, as shown in Fig. 2, DAB maintains the DC-link voltage and inverter controls the power output [20]. In order to improve the dynamic behavior, a feed forward loop, as shown in Fig. 2, is often implemented to the power loop (current loop) [22].

DAB and inverter have different dynamic behaviors, because of the differences in topologies, control schemes, and uncertain parasitic parameters, so the power unbalance on DC-link capacitor will occur during transitions, which results in voltage fluctuations on the DC-link. Without effective control, the DClink voltage $V_{d c}$ may become unacceptable, which not only causes distortions in the grid current, but also increases the stress on the switching devices, even may damage the DABCI.

\section{A. DAB Converter Modeling and Control}

The DAB converter consists of two H-bridges, and they are connected by a high or medium frequency transformer. The power flow can be controlled by the phase-shift between the two bridges [11]. The main circuit and operating waveforms are shown in Fig. 3, and the average input current $I_{1}$ is (1), and DAB output power is (2). [23].

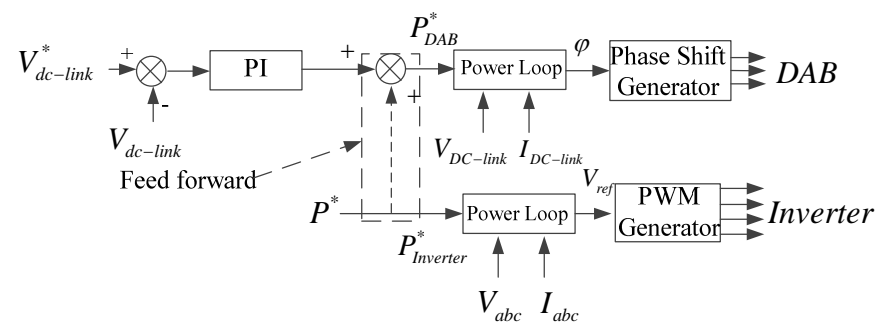

Fig. 2 Conventional power control of the DABCI

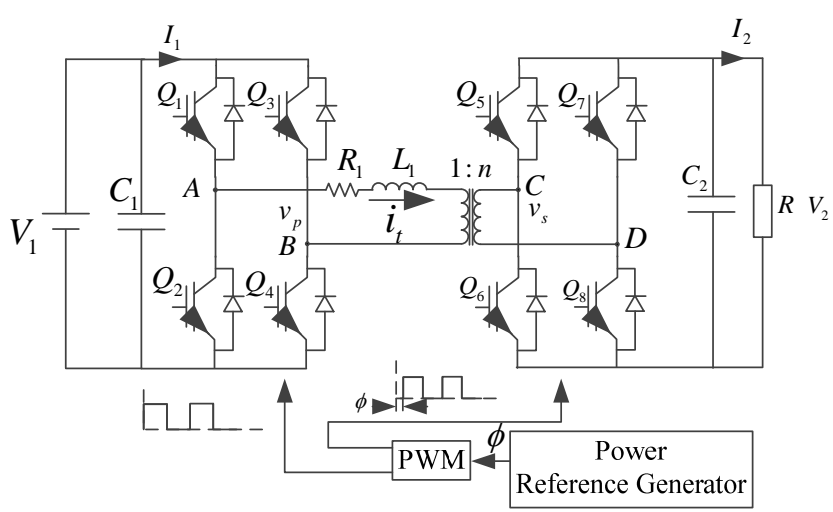

(a) DAB converter and its power control

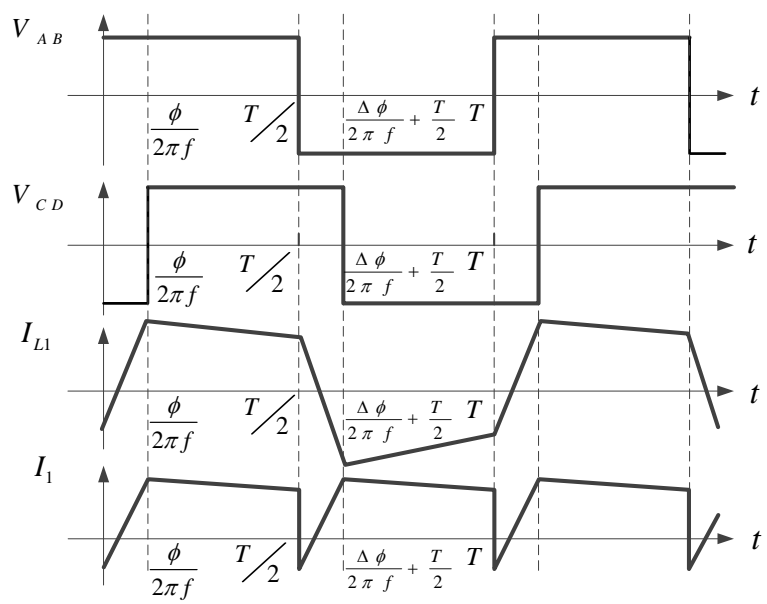

$V_{A B}$-Transformer primary side voltage $\quad I_{L 1}$-Transformer primary side current $V_{C D}$-Transformer secondary side voltage $\quad I_{1}$-Primary side H-bridge input current

(b) DAB operating wave forms ( $\mathrm{n}$-turn ratio )

Fig. 3 DAB control diagram and main wave forms

$$
I_{1}=\frac{n V_{2}}{2 \pi^{2} f L_{1}} \phi(\pi-|\phi|)
$$

where $n$ is the transformer turn ratio between the primary side and secondary side. $V_{2}$ is the output voltage. $f$ is the switching frequency, and $\emptyset$ is the phase shift between the two bridges.

$$
P=\frac{n V_{1} V_{2}}{2 \pi^{2} f L_{1}} \phi(\pi-|\phi|)
$$

As in (2), when $\varnothing$ is $\frac{\pi}{2}, P$ will be the maximum value. The maximum power can be increased by reducing the switching frequency or the leakage inductance.

Suppose $v_{p}$ and $v_{s}$ are respectively the transformer primary and secondary side voltages; $s_{1}(t)$ and $s_{2}(t)$ are the switching functions of the primary and secondary side respectively, then the modeling of the DAB converter can be shown as:

$$
\begin{gathered}
v_{p}=s_{1}(t) V_{1}(t) \\
v_{s}=s_{2}(t) V_{2}(t)=\left\{\begin{array}{c}
1,0<t=\frac{T}{2} \\
-1, \frac{T}{2}<t=T
\end{array}\right.
\end{gathered}
$$




$$
s_{2}(t)=\left\{\begin{array}{cc}
1, \quad & \frac{\phi T}{2 \pi}<t=\frac{T}{2}+\frac{\phi T}{2 \pi} \\
-1,0<t= & \frac{\phi T}{2 \pi} \text { OR } \frac{T}{2}+\frac{\phi T}{2 \pi}<t=T+\frac{\phi T}{2 \pi}
\end{array}\right.
$$

where $T$ is the switching period. Select the transformer primary side current $i_{t}$ and output capacitor voltage $V_{2}$ as state variables, the state equations of a $\mathrm{DAB}$ converter can be derived as:

$$
\begin{gathered}
\frac{d i_{t}(t)}{d t}=-\frac{R_{1} i_{t}(t)}{L_{1}}+\frac{n s_{1}(t) V_{1}(t)}{L_{1}}-\frac{s_{2}(t) V_{2}(t)}{L_{1}} \\
\frac{d V_{2}(t)}{d t}=\frac{s_{2}(t) \frac{i_{t}(t)}{n}}{C_{2}}-\frac{i_{o}(t)}{C_{2}}
\end{gathered}
$$

With the Fourier analysis [24-26], the state equations can be expressed as:

$$
\begin{gathered}
\frac{d x}{d t}=A x+B \phi \\
y=C x \\
x=\left[\Delta V_{2} \Delta i_{t 1 R} \Delta i_{t 11}\right] \\
y=\Delta V_{2} \\
A=\left[\begin{array}{ccc}
-\frac{1}{R C_{2}} & \frac{-4 \sin (\phi)}{\pi C_{2}} & \frac{-4 \cos (\phi)}{\pi C_{2}} \\
\frac{2 \sin (\phi)}{\pi L_{1}} & -\frac{R_{1}}{L_{1}} & w_{s} \\
\frac{2 \cos (\phi)}{\pi L_{1}} & -w_{s} & -\frac{R_{1}}{L_{1}}
\end{array}\right] \\
B=\left[\begin{array}{cc}
\frac{4}{C_{2}}\left(I_{0 I} \sin (\phi)-I_{O R} \cos (\phi)\right) \\
\frac{2 V_{2}}{L_{1}} \cos (\phi) \\
\frac{-2 V_{2}}{L_{1}} \sin (\phi) \\
C=\left[\begin{array}{ll}
1 & 0
\end{array}\right](14)
\end{array}\right]
\end{gathered}
$$

where $i_{t 1 R}$ and $i_{t 1 I}$ are the real part and imaginary part of the transformer current.

$$
w_{s}=2 \pi f
$$

The transfer function of the DAB converter is

$$
G=C(s I-A)^{-1} B
$$

Fig. 4 (a) is the power control block diagram of DAB. $I_{2}$ is the output current of DAB, which is determined by the load. From Fig. 4 (b), it can be seen that the dynamic behavior of

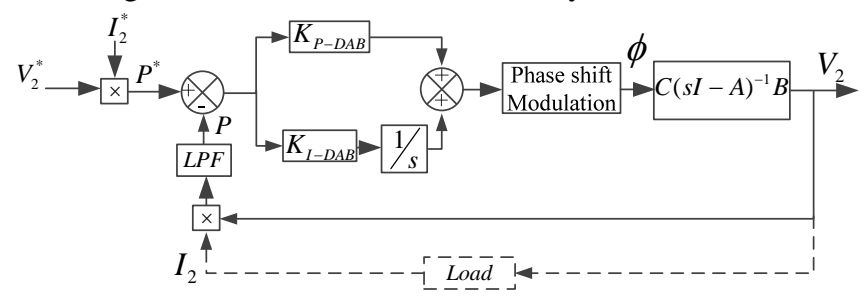

(a)DAB control diagram

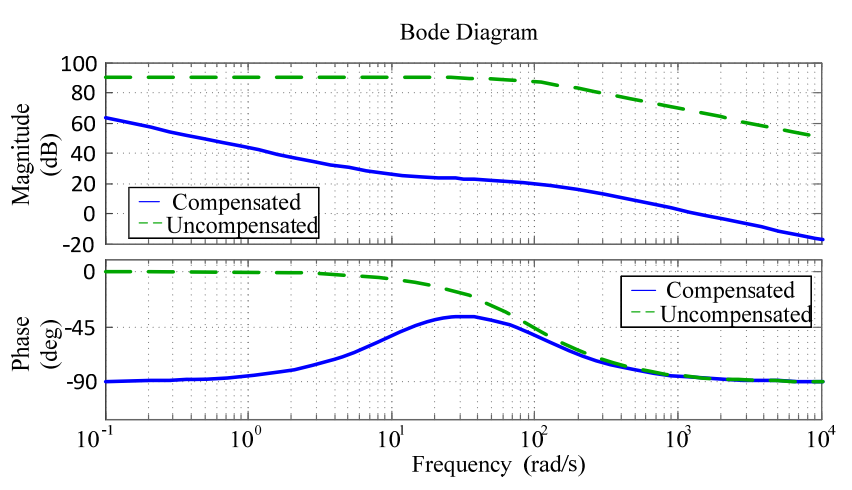

(b)DAB Bode plots

Fig. 4 DAB control unit and bode plots

power control is related to the voltage control loop. Based on above modeling, the power controller can be designed, and Fig. 4 (b) shows the bode plots of the DAB under voltage control, with and without compensation. Parameters are shown in the Appendix.

\section{B. Inverter Modeling}

Fig. 5(a) and (b) show the inverter topology and model. $r$ is the parasitic resistance of the inductor, and $K_{P W M}$ is the amplitude of triangular carrier wave in the SPWM modulation. The item of $V_{d c} / 2 K_{P W M}$ is the gain between the output voltage and the reference wave. Fig. 6 is the inverter control diagram. As shown, through Park transformation, the current loop is performed under DQ rotation reference frame [27], and the power can be calculated as:

$$
\begin{gathered}
P=\frac{3}{2}\left(U_{d} I_{d}+U_{q} I_{q}\right) \\
Q=-\frac{3}{2}\left(U_{d} I_{q}-U_{q} I_{d}\right)
\end{gathered}
$$

where $U_{d}, U_{q}$ are the voltage on $\mathrm{D}$ and $\mathrm{Q}$ axis respectively, and $I_{d}, I_{q}$ are respectively the $\mathrm{D}$ and $\mathrm{Q}$ axis current. If the $\mathrm{D}$ axis is oriented along the grid voltage vector position, $U_{q}$ is 0 , and then the current references can be expressed as:

$$
\begin{gathered}
I_{d}^{*}=\frac{2}{3} \frac{P^{*}}{U_{d}} \\
I_{q}^{*}=-\frac{2}{3} \frac{Q^{*}}{U_{d}}
\end{gathered}
$$

where $P^{*}$ and $Q^{*}$ are the power references; $I_{d}^{*}$ and $I_{q}^{*}$ are the current reference on the $\mathrm{D}, \mathrm{Q}$ axis respectively.

As shown in Fig. 6, the current loop uses PI controllers to track the current references, and then generate the PWM signals to drive the switches [28]. the inductor current $I_{L}(s)$ is (22):

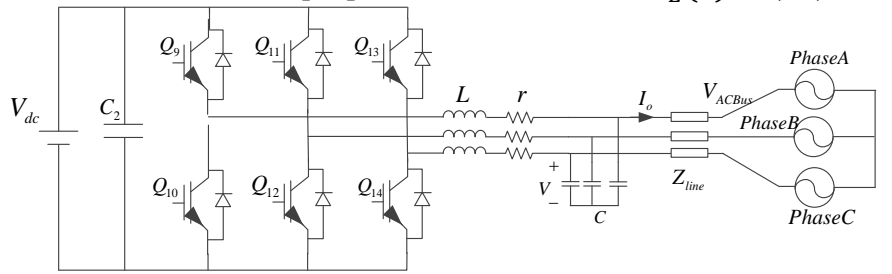

(a)Main circuit of the inverter 


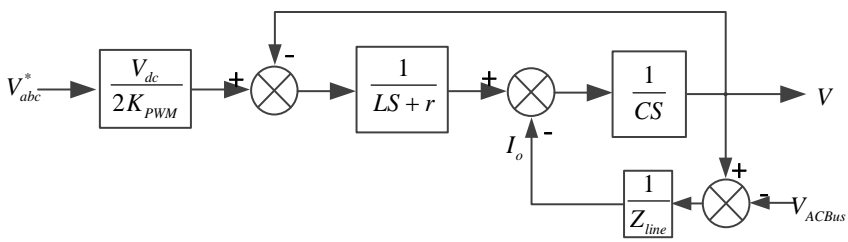

(b)Systematic model of the inverter

Fig. 5 Inverter main circuit and systematic model

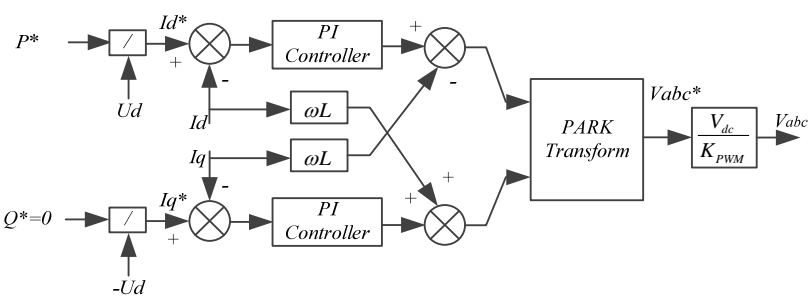

Fig. 6 Inverter control block diagram with current control

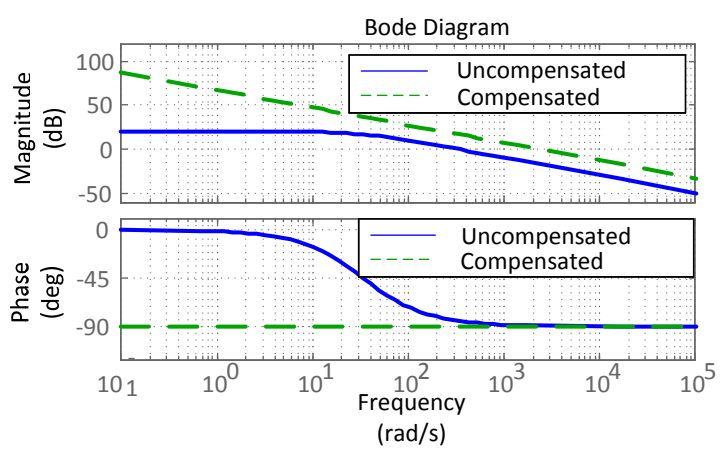

Fig. 7 The bode plots of the current controlled inverter

$$
\begin{aligned}
& I_{L}(s)=\frac{1}{L C Z_{\text {line }} s^{2}+\left(L+r C Z_{\text {line }}\right) s+1+r} \frac{V_{d c}}{2 K_{P W M}} I^{*}(s)+ \\
& \cdot \frac{L C s^{2}+C r s+1}{L C Z_{\text {line }} s^{2}+(L+r C Z) s+1+r} V_{\text {ACBus }}(s)
\end{aligned}
$$

where $L C$ are respectively the inductance and capacitance of the LC filter, $Z_{\text {line }}$ is the transmission line impedance and $V_{d c}$ is the input DC voltage. As shown, the inductor current is determined by both the current reference $I^{*}(s)$ and the $V_{A C B u s}$.

In order to lower the current loop response to the switching noises, the bandwidth of current loop is much narrower than the switching frequency [29]. The ratio of $K_{p}$ and $K_{i}$ is equal to the ratio of $L$ and the parasitic resistance $r$, as (23), so the model of the current loop becomes a reduced order system, which is more easily controlled [28].

$$
\frac{K_{p}}{K_{i}}=\frac{L}{r}
$$

The bode diagram of the current loop is shown in Fig. 7.

The control bandwidth of inverter is narrower than that of the $\mathrm{DAB}$, which means that the $\mathrm{DAB}$ converter is faster than the inverter. This will be used for the following analysis. The parameters are shown in the appendix.

\section{Analysis of DC-link Voltage Fluctuations}

As shown in Fig. 2, the DAB is used to control DC-link voltage and inverter to control power. Normally, the DAB and inverter have different dynamic behaviors, so during transitions, power unbalance on DC-link capacitor will occur, which will alter the DC-link voltage. The relation between DClink voltage variation and power unbalance can be expressed as:

$$
\Delta V_{d c}=\sqrt{V_{d c}^{2}+\frac{2\left(E_{D A B}-E_{\text {Inverter }}\right)}{C}}-V_{d c 0}
$$

where $V_{d c}$ is the voltage on the DC-link capacitor, which is also the input DC voltage for the inverter. $V_{d c 0}$ is the nominal DClink voltage. $E_{D A B}$ and $E_{\text {Inverter }}$ are respectively the output energy of $\mathrm{DAB}$ and inverter, which can be obtained by the integration of power output. $C$ is the DC-link capacitor.

According to (22), the small signal of inverter output current can be expressed as

$$
\begin{aligned}
& \dot{I}(s)=\frac{1}{L C Z_{\text {line }} s^{2}+\left(L+r C Z_{\text {line }}\right) s+1+r} \frac{V_{d c}}{2 K_{P W M}} \tilde{I}^{*}(s) \\
& +\frac{1}{L C Z_{\text {line }} s^{2}+\left(L+r C Z_{\text {line }}\right) s+1+r} \frac{I^{*}(s)}{2 K_{P W M}} \nabla_{d c}^{\|}
\end{aligned}
$$

where the superscript $\wedge$ represents the relevant small signal. From (24) and (25), it can be seen that the variation of DC-link voltage will affect the output inverter current, so a stable DClink voltage is necessary for improving the performance of inverter.

Normally, the DC-link voltage controlling converter's control is designed by its own feature [30]. The voltage controller is designed based on the DAB model [26], and the block diagram is shown in Fig 8. In Fig 8, the block diagram is presented through the view of energy, so $V_{d c}^{2}$ is used here. The energy stored on the DC-link capacitor is $\frac{1}{2} C V_{d c}^{2}$ and the integration of power difference between $\mathrm{DAB}$ and inverter is the energy variation on the DC-link capacitor, which causes the DC-link voltage fluctuation. The energy output of DAB and inverter can be obtained by the product of power references $\left(P_{D A B}^{*}, P_{I N V}^{*}\right)$ with the transfer function of power $\operatorname{control}\left(G_{D A B}(s), G_{I N V}(s)\right)$.

By neglecting the high order item, the small signal of $V_{d c}$ is linear with $V_{d c}^{2}$, as:

$$
V_{d c}^{* 2}-\left(V_{d c}^{*}+\Delta V_{d c}\right)^{2} \approx\left[V_{d c}^{*}-\left(V_{d c}^{*}+\Delta V_{d c}\right)\right] \mathrm{g} 2 V_{d c}^{*}
$$

where $\Delta V_{d c}$ is the small signal perturbation. Based on Fig. 8, the voltage controller can be designed. The uncompensated open loop transfer function for the voltage control loop is (27).

Compensated with PI controller, the closed loop bode plots of voltage control is shown in Fig 9. The parameters are shown in the Appendix. In the following analysis, all the compared control methods will use the same parameters.

As shown in Fig 8, the power reference $\left(P^{*}\right)$ is interference to the DC-link voltage control. The interference model is shown in Fig. 10. As shown, the DAB loop is a closed loop for

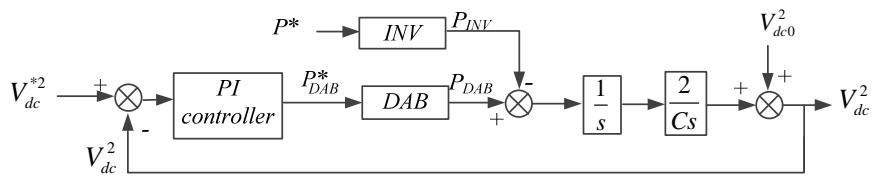

Fig 8 Block diagram of the DAB converter with voltage control 

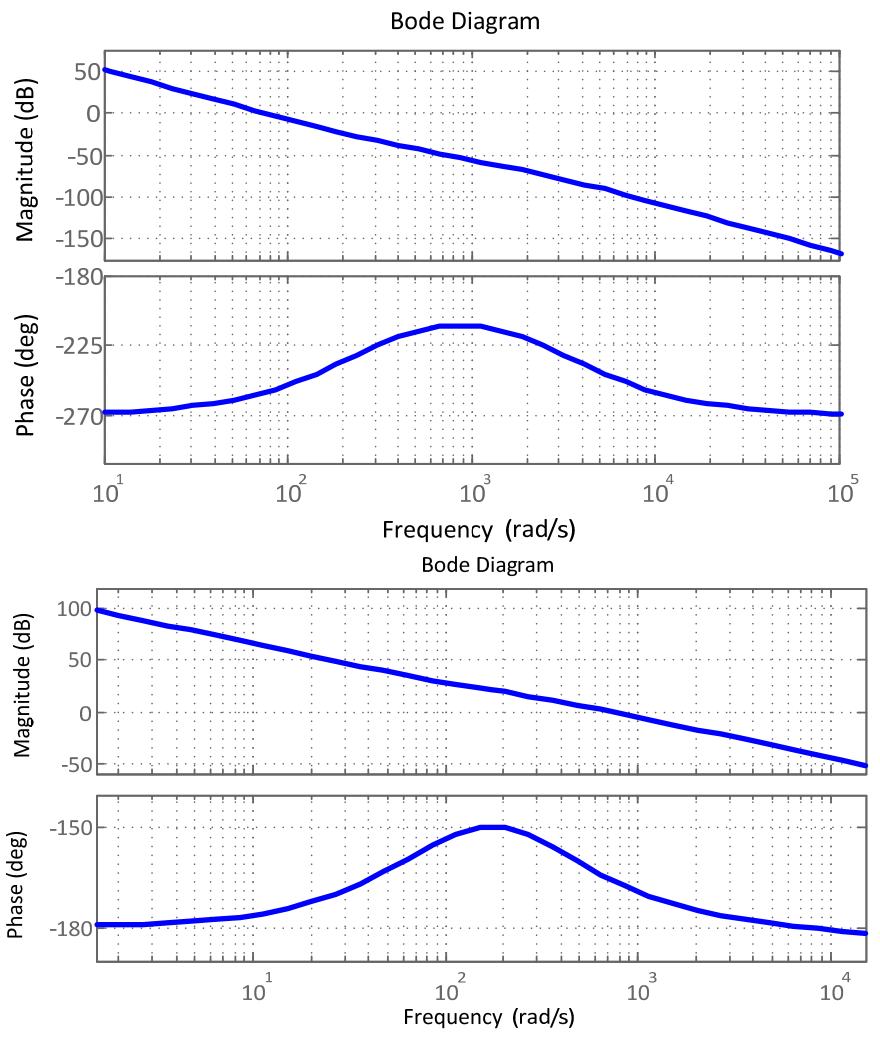

Fig 9 Bode plots of DAB converter with voltage control

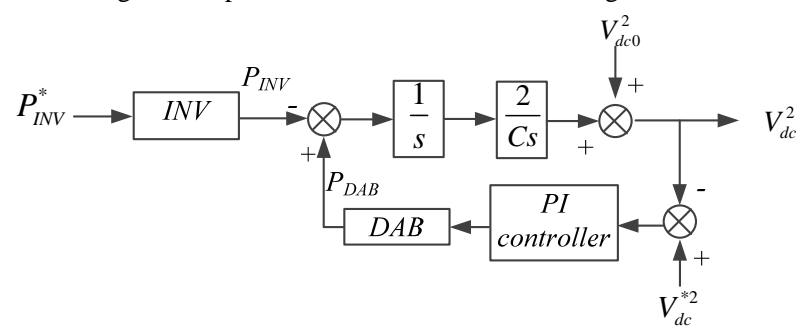

Fig. 10 Small signal blocks of the interference effect on the DC voltage

the DC-link voltage control, but for the inverter behaves as an open loop for the DC-link voltage control.

$$
G(s)=\frac{2 G_{D A B}(s)}{C s}
$$

Equation (28) is the interference transfer function, with the input of power reference, and output of DC-link voltage.

$$
G_{1}(s)=\frac{D C-\text { link voltage }}{\text { Power Rference }}=\frac{-\frac{2}{C s} G_{I N V}(s)}{1+G_{D A B}(s) G_{P I}(s) \frac{2}{C s}}
$$

With the same voltage controller, the $\mathrm{DAB}$ converter and inverter exchange the responsibility of power control and DClink voltage control, and Fig. 11 shows the bode plot of the interference transfer function. As shown in Fig. 11, when DAB maintaining DC-link voltage, at high frequency domain, higher than $158 \mathrm{rad} / \mathrm{s}$, the amplitude gain of DC voltage fluctuation is smaller than the one with inverter controlling the DC-link voltage, which means the interference caused by the power reference variations can be damped more effectively.

As mentioned before, DAB control bandwidth is greater than the inverter, so when DAB maintains the DC-link voltage, the equivalent feed-back loop in Fig. 10 will be faster, then the power output variation of the inverter can be tracked more quickly, which can reduce the DC-link voltage fluctuations. But the DC-link voltage still faces the challenge of transient voltage fluctuations, because the voltage control is based on the DClink voltage offset from the nominal value. The discussion

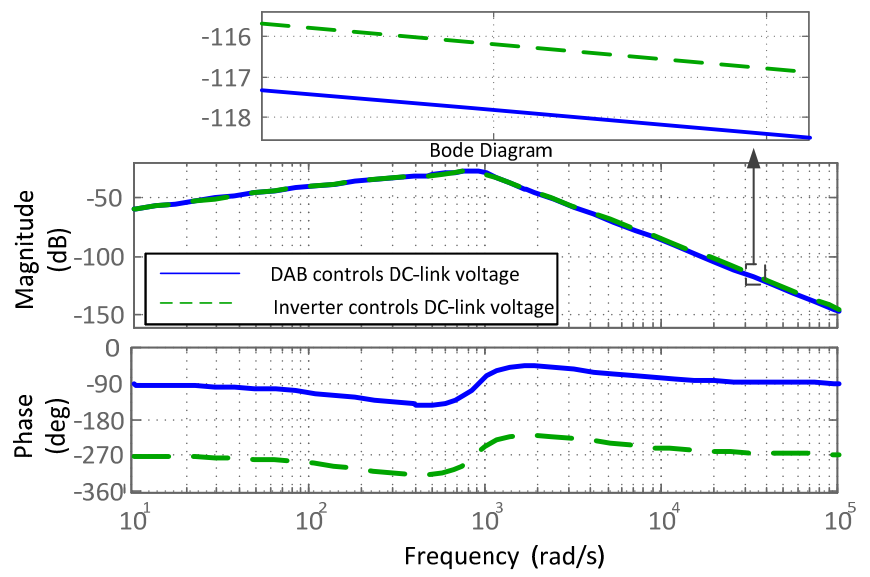

Fig. 11 Bode plots of the DC-link voltage fluctuations in cascaded system

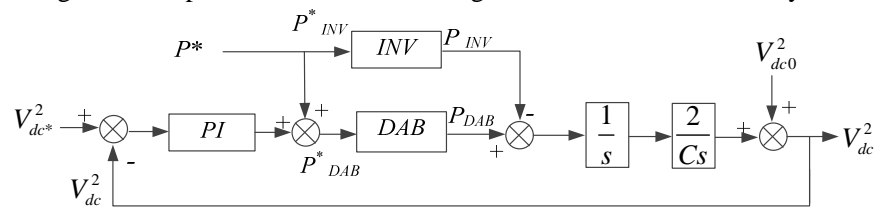

Fig. 12 Control block of the cascaded system added with feed forward.

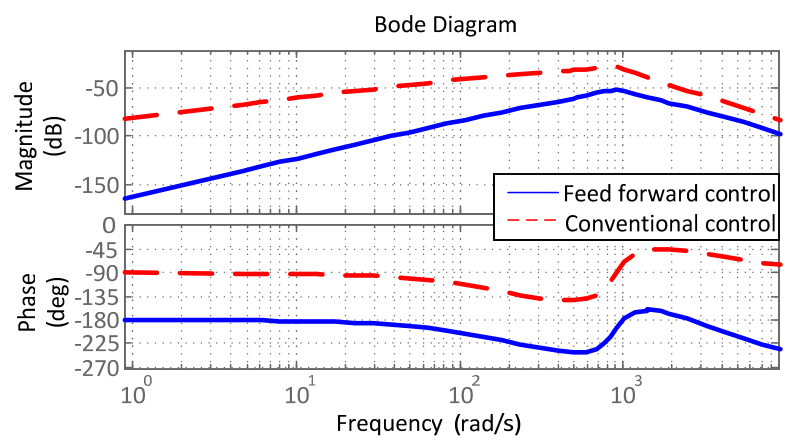

Fig. 13 The compared bode plots conventional control with feed forward control

of this paper is based on this optimized condition with the faster DAB converter controlling DC-link voltage.

As shown in Fig. 2, a feed forward path is usually introduced to improve the performance of the cascaded system. Fig. 12 is the DC-link voltage control diagram of the feed forward control, and (29) is the interference transfer function on the DC-link voltage.

$$
G(s)=\frac{D C-\text { link voltage }}{\text { Power Reference }}=\frac{\left(G_{D A B}(s)-G_{I N V}(s)\right) \frac{2}{C s}}{1+G_{D A B}(s) G_{P I}(s) \frac{2}{C s}}
$$

Fig. 13 shows the interference bode plot of the feed forward control, in comparison with the conventional control. As shown in Fig. 13, the gain of the feed forward control is much smaller than conventional control, which means under the same variation of power reference, the DC-link voltage of the feed forward control has smaller fluctuations. 


\section{Active Power And DC-Link Voltage CoORdinAtive CONTROL}

\section{A. Active power and DC-link voltage coordinative control}

This paper proposes an active power and DC-link voltage coordinative control, which can reduce the DC voltage

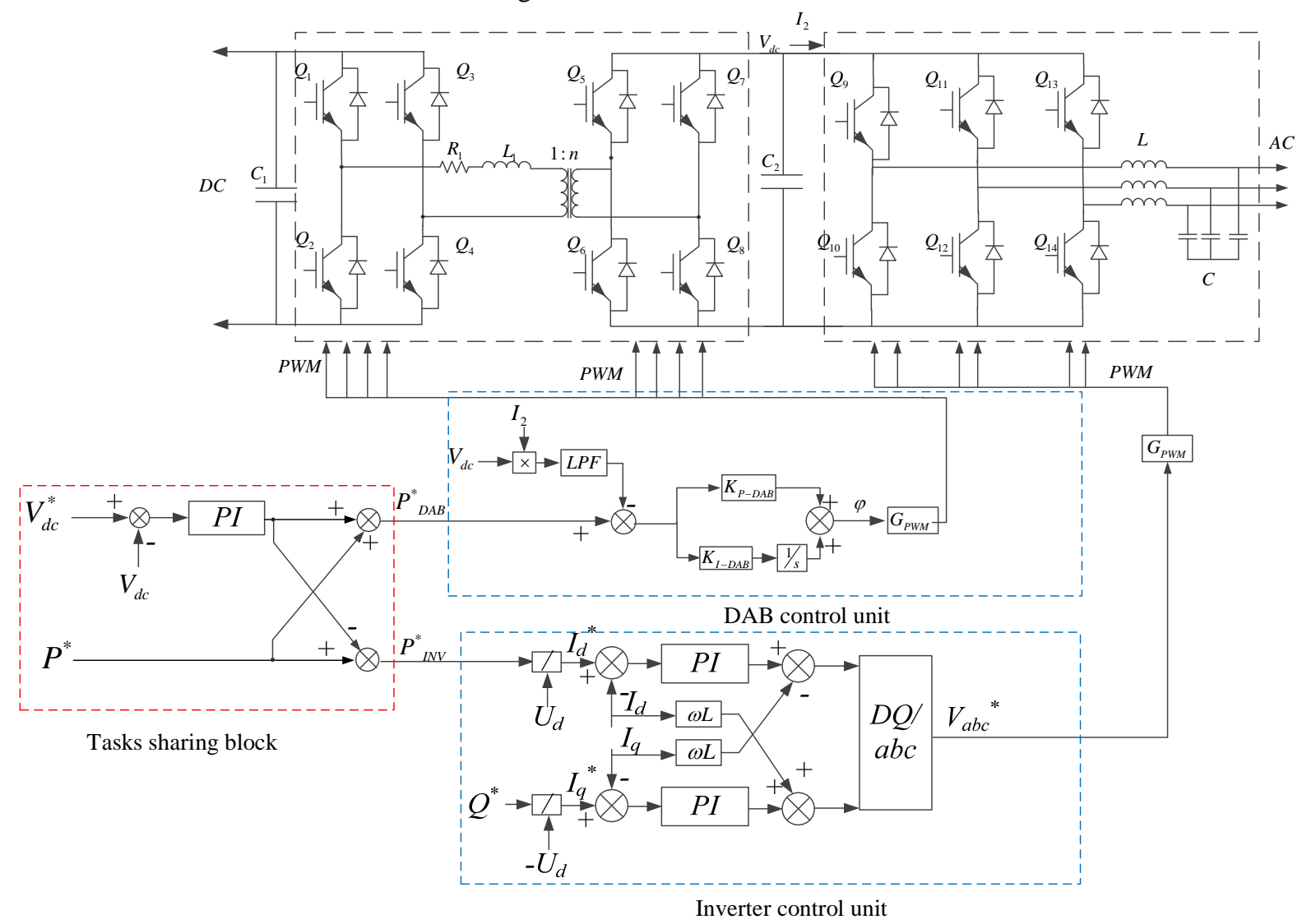

Fig. 14. The scheme of the proposed coordinative control for DABCI.

fluctuations. It implements the $\mathrm{DAB}$ and inverter to share the tasks of DC-link voltage control and the power control. The proposed control scheme is shown in Fig. 14. As shown, the tasks sharing block generates the power reference for the DAB $\left(P_{D A B}^{*}\right)$ and inverter $\left(P_{I N V}^{*}\right) . P_{D A B}^{*}$ is the sum of the power reference $\mathrm{P}^{*}$ with the output of the DC-link voltage controller.

$P_{I N V}^{*}$ is that $P^{*}$ subtracts the output of DC-link voltage controller, because the DAB and inverter regulate the DC-link voltage by the power in opposite direction, for instance, to increase the DC-link voltage, the DAB needs to increase power output and the inverter needs to decrease power output. DAB and inverter control units drive the converters to output the reference values. The parameters in the proposed control are the same as that used the conventional control and feed forward control.

Fig. 15 is the circuit of DC-link capacitor, as shown, the DC link voltage is the integration of the current difference between DAB and inverter, as shown in (30).

$$
V_{D C-\text { link }}=\frac{1}{C_{D C-\text { link }}} \int I_{D A B} d t-\frac{1}{C_{D C-\text { link }}} \int I_{I N V} d t
$$

Conventional control only uses DAB to control the DC link voltage, so the inverter current is interference for the DC link voltage control. Feed-forward control shares the current reference with $\mathrm{DAB}$ and inverter, but under steady state or when the power reference stays the same, only DAB controls the DC-link voltage, then the feed forward control is the same as conventional control. In the proposed control, the DC-link voltage control is achieved by both $\mathrm{DAB}$ and inverter all the time, so the DC-link voltage control becomes closed loop for both the DAB and inverter.

In the proposed control, each sub converter can have its own DC-link voltage controller, but with different voltage controller, the system order will be higher, which deteriorates the system stability, so the proposed control uses the same voltage controller for the DAB and inverter.

With the same controller, the DAB and inverter control the DC link voltage simultaneously, and act in the same direction. For example, if the DC-link voltage is over the reference value, the $\mathrm{DAB}$ converter will reduce power output to decrease the DC-link voltage, and inverter will increase power output to decrease the DC-link voltage, so the inverter helps the DAB control the DC link voltage, not compete, and this can avoid the cross regulation issue. 


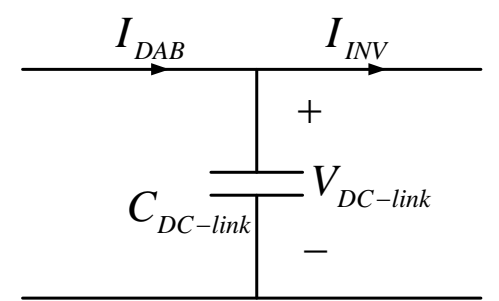

Figure 15 DC-link voltage and current

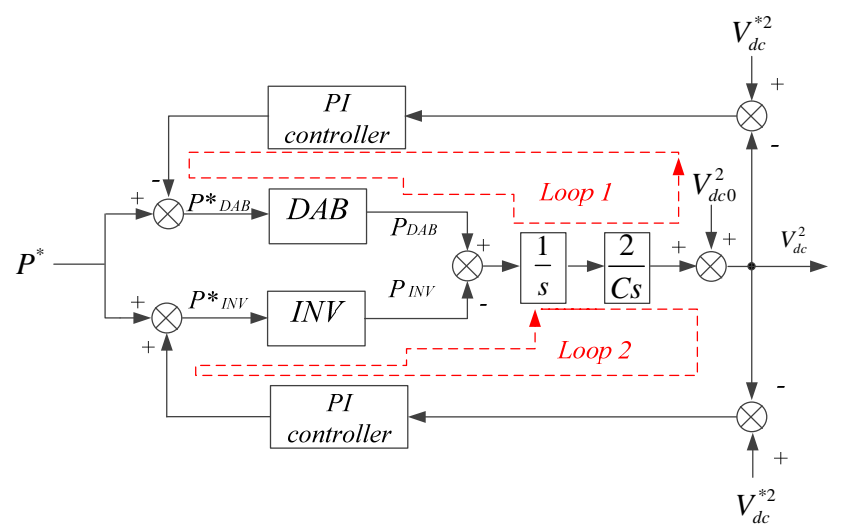

Fig 16 Control block of the proposed DC-link voltage and power coordinative control

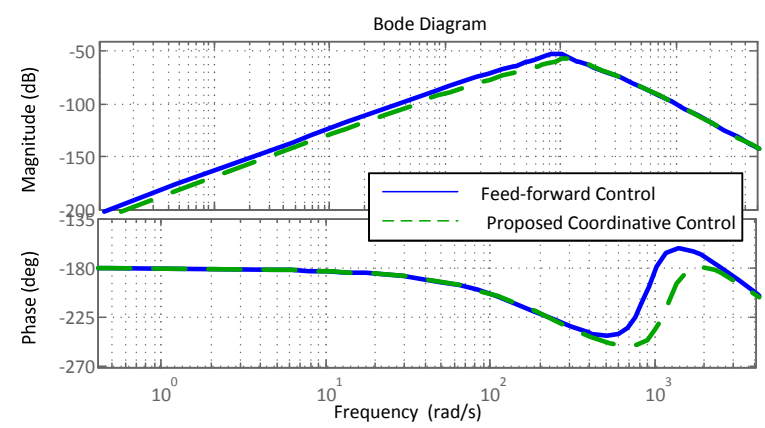

Fig. 17 Compared interference bode plots of the coordinative control with feed forward control

Fig 16 is the interference block diagram of the proposed control method, from power reference to the DC-link voltage. Compared with conventional control in Fig. 10, loop 2 and the power reference feed-forward loop are added to enhance the DC-link voltage control. The controller parameters are the same as conventional control.

$$
\begin{aligned}
& G(s)=\frac{V_{d c}(s)}{P^{*}(s)}= \\
& \cdot \frac{\left(G_{D A B}(s)-G_{I N V}(s)\right) \frac{2}{C s}}{1+G_{D A B}(s) G_{P I}(s) \frac{2}{C s}+G_{I N V}(s) G_{P I}(s) \frac{2}{C s}}
\end{aligned}
$$

Compared with the feed forward control, the proposed control introduces the inverter feed-back loop to the DC-link voltage control, so the item of $2 G_{I N V}(s) G_{P I}(s) /\left(C s^{2}\right)$ is added to the dominator in (31), so the dominator is larger than the one in (29), representing the gain of voltage fluctuation is smaller than (29). Fig. 17 is the bode plot of the proposed control and the feed-forward control. As shown, in the proposed coordinative control, the interference magnitude is always smaller than the feed forward control, 6.9dB less, which means under the same power reference variation, the DC-link voltage fluctuation of coordinative control is smaller than a half of the feed forward control, much smaller than conventional control.

When the power reference is constant, the power reference interference can be neglected. Fig 18 is the DC-link voltage control of the feed forward control and the proposed control. As shown in Fig 18 (a) (b), in the proposed control, the double converter regulation has both $\mathrm{DAB}$ and inverter to control DC

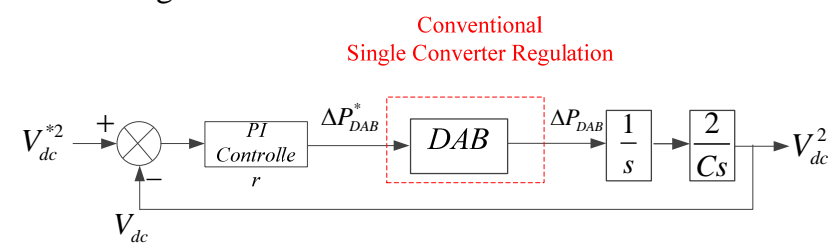

(a)DC-link voltage control diagram of feed-forward control Proposed

Double Converter Regulation

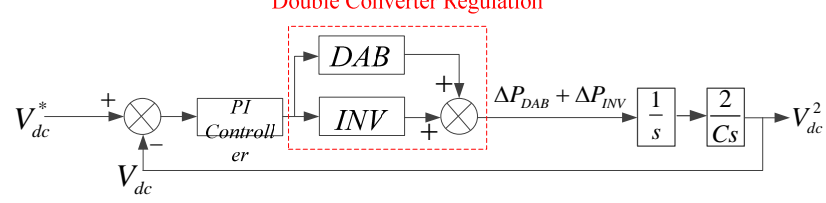

(b)DC -link voltage control diagram of the proposed control

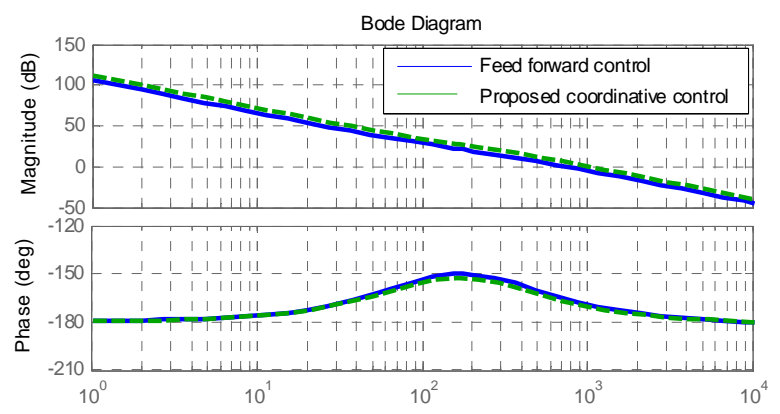

(c) Bode plots of the feed forward control and the proposed control Fig 18 DC-link voltage control of the Feed forward control and proposed control

link voltage, so it has a larger equivalent gain than the conventional single converter regulation.

Fig 18 (c) is the open loop bode plot of the feed forward control and the proposed control. As shown, the proposed control enlarges the control bandwidth of the DC-link voltage control.

To make a fair comparison with the conventional control and feed forward control, the parameters of the voltage controller varied from $\frac{\mathbf{1}}{\mathbf{1 0}}$ times to 10 times of previous value to verify the improvement. Here the voltage controller is the PI controller in charge of DC-link voltage control, as shown in Fig. 10, Fig. 12, Fig. 14 and Fig 18 (a) (b). It can be expressed as:

$$
G_{P I}(s)=K \frac{\tau s+1}{\tau s}
$$

where $K$ is the gain of the controller, $\tau$ is the integral time.

As shown in Fig 18 (a) (b), the gain of this controller directly affects the DC-link voltage control open loop transfer function. So with the increment of this controller gain, the DC-link 
voltage control will be faster, and under the decrement of $K$, the DC-link voltage control becomes slower. Then the DC-link voltage interference in feed-forward control and the proposed control can be compared in the respect of damping performance on the DC-link voltage fluctuation.

Fig 19 is the interference bode plot with the voltage controller gain- $K 10$ times enlarged and reduced to one tenth. As shown, with enlarged controller gain, the interference gains from power reference to DC-link voltage are decreased, with $15 \mathrm{~dB}$ smaller than in Fig. 13 and Fig. 17, which means the

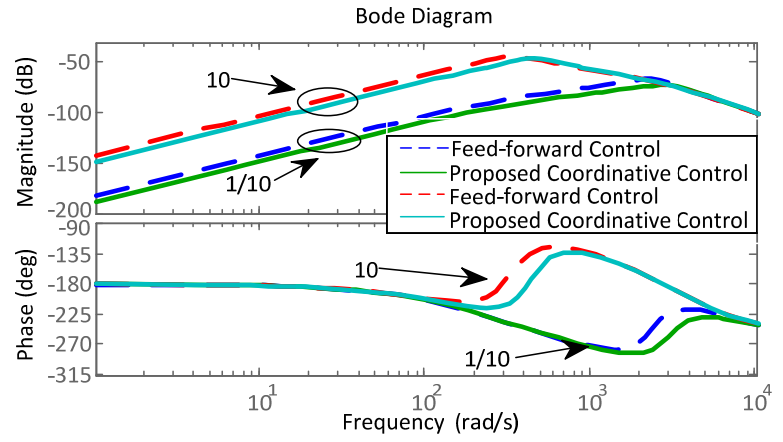

Fig 19 Compared interference bode plots of the coordinative control with feed forward control
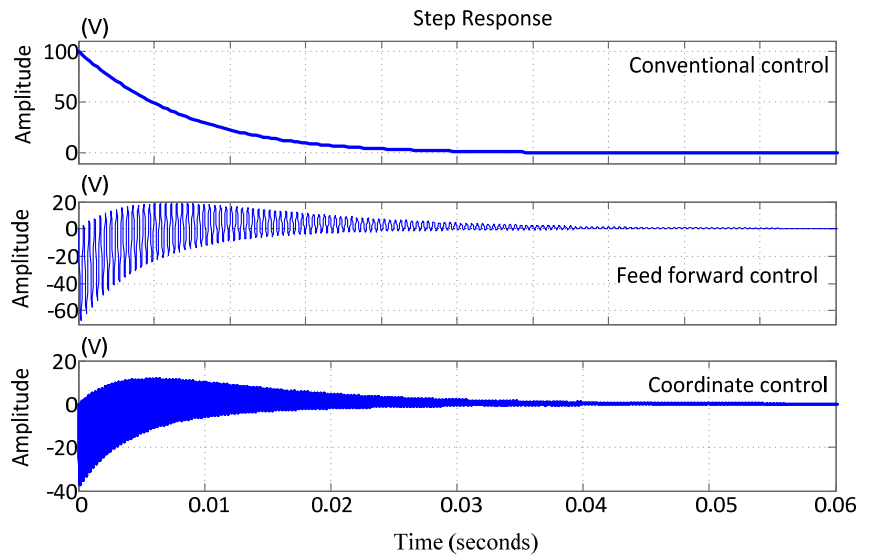

Figure 20 -10kW Step response of the voltage fluctuation

DC-link voltage fluctuations will be more suppressed. When the voltage controller gain $K$ decreases to $\frac{1}{10}$ times, the interference gains increases by $7.3 \mathrm{~dB}$, which means the DClink voltage fluctuations become less suppressed. But no matter the voltage controller is increased or decreased, the interference gain of the proposed control is always $6 \mathrm{~dB}$ smaller than feed forward control. So with the variation of voltage controller gain, the proposed control still damps the DC-link voltage fluctuations more effectively than the feed forward control.

Added with the conclusion obtained by Fig. 11, within the stability area, a greater power (current) controller makes the converter faster, and with faster converter control DC-link voltage, the voltage fluctuations would become smaller.

For the voltage controller, within the stability area, a higher gain of voltage controller can suppress the DC-link voltage fluctuations more effectively.

With the model in Fig 16 and the parameters in the Appendix, the voltage step response under the $-10 \mathrm{~kW}$ power reference variation (from $5 \mathrm{~kW}$ to $-5 \mathrm{~kW}$ ) can be obtained, as in
Fig 20. The $10 \mathrm{~kW}$ response figure will be symmetric with the zero axis with Fig 20. So when the power reference changes between $-5 \mathrm{~kW}$ and $5 \mathrm{~kW}$ repeatedly, the peak values of voltage fluctuation is $198 \mathrm{~V}$ in conventional control, $136 \mathrm{~V}$ in feed forward control and $74 \mathrm{~V}$ in the proposed control. Later the data will be compared with simulation results.

\section{B. Stability analysis with root locus}

Fig. 21 is the root locus of the conventional control,

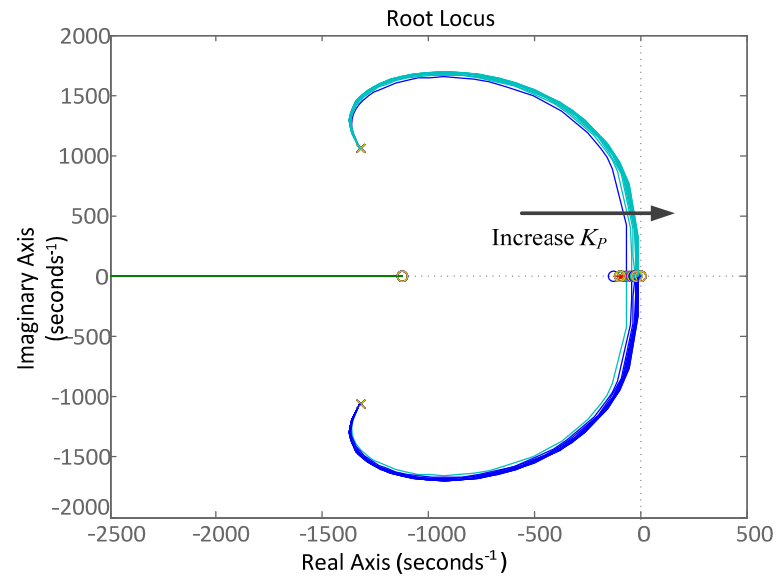

Fig. 21 Root locus of conventional control

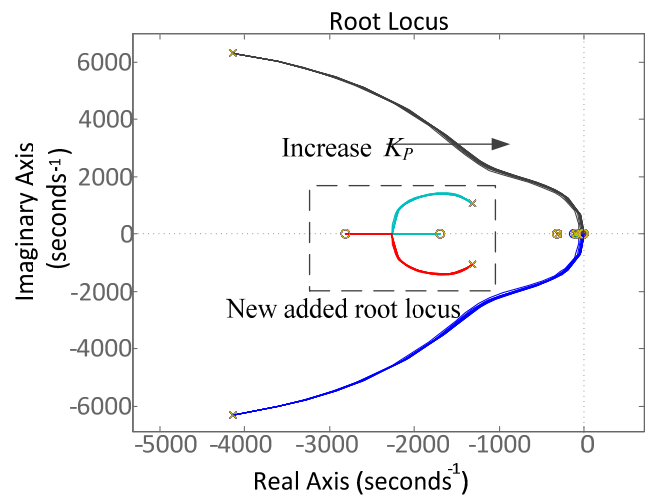

Fig. 22 Root locus of active power and DC voltage coordinative control

obtained from (28), with the parameter $K_{P}$ in $G_{P I}(s)$ increasing from 40 to 400 . As shown, with the increasing of $K_{P}$, the roots moves towards the imaginary axis, indicating that the bigger the gain is, the less stable the system will be. For the feed forward control, power reference feed forward is introduced, but the characteristic equation of the feed forward control is still the same as the conventional control, as shown in (28) and (29), so the stability of the feed forward control is the same as conventional control. Fig. 22 is the root locus of the proposed coordinative control, obtained from (31).

As shown, two pairs of zero-poles are added, but they locate on the left side of the plane, even further to the imaginary axis than previous roots, so the system is stable with the proposed control.

With more firmly controlled DC-link voltage, the stress of DC-link capacitor will also be reduced. The DC-link capacitor is not only to minimize the voltage ripple under steady state, but also to ensure the stability of the cascaded system [31]. The stability of the cascaded converter system not only depends on well designing of individual converter, but also the input and 
output impedance of sub-converters [32]. The input impedance is equivalent impedance viewed from a power source connected to the network [33], and output impedance is the impedance exhibited by its output terminals to an alternating current of a particular frequency [34]. If the output impedance of a source converter is much less than the input impedance of the load converter, then the stability of cascaded system can be guaranteed [35]. Normally, an intuitive way to reduce the source converter's output impedance is adding an intermediate bus capacitor to the cascaded system, and the calculation of DClink capacitor is shown in [31]. The impedance interaction in cascaded system can be expressed as [36]:

$$
T_{m}=\frac{Z_{\text {o-source }}}{Z_{\text {in-load }}}
$$

where $T_{m}$ is the impedance interaction, and $Z_{o \text {-source }}$ is the output impedance of source converter, and $Z_{\text {in-load }}$ is the input impedance of load converter.

The output and input impedance of converter can be obtained as

$$
\begin{gathered}
Z_{\text {o-source }}=-\frac{\Delta V_{o}}{\Delta I_{o}} \\
Z_{\text {in-load }}=\frac{\Delta V_{\text {in }}}{\Delta I_{\text {in }}}
\end{gathered}
$$

where $\Delta \boldsymbol{V}_{\boldsymbol{o}}$ and $\Delta \boldsymbol{I}_{\boldsymbol{o}}$ are the output voltage and output current variations, $\Delta \boldsymbol{V}_{\text {in }}$ and $\Delta \boldsymbol{I}_{\text {in }}$ are the input voltage and input current variations. In the cascaded system, the output voltage of source converter and the input voltage of load converter are both the DC-link voltage $\boldsymbol{V}_{\boldsymbol{d} \boldsymbol{c}}$. When the DC-link voltage has perturbation of $\Delta \boldsymbol{V}_{\boldsymbol{d} \boldsymbol{c}}$, the output current variation of DAB converter $\left(\Delta \boldsymbol{I}_{\boldsymbol{o}}\right)$ and the input current variation of inverter $\left(\Delta \boldsymbol{I}_{\text {in }}\right)$ are respectively.

$$
\begin{gathered}
\Delta I_{o}=\frac{\Delta P}{V_{o}}=-\frac{\Delta V_{d c} G_{P I}(s) G_{D A B}(s)}{V_{d c}+\Delta V_{d c}} \\
\Delta I_{i n}=\frac{\Delta P}{V_{o}}=\frac{\Delta V_{d c} G_{P I}(s) G_{I N V}(s)}{V_{d c}+\Delta V_{d c}}
\end{gathered}
$$

Then the output impedance of source converter and input impedance of load converter can be expressed as

$$
\begin{aligned}
& Z_{o}=\frac{V_{d c}+\Delta V_{d c}}{G_{P I}(s) G_{D A B}(s)} \\
& Z_{i n}=\frac{V_{d c}+\Delta V_{d c}}{G_{P I}(s) G_{I N V}(s)}
\end{aligned}
$$

The control scheme is symmetric, and then source converter output impedance and load converter input impedance will be similar within the control bandwidth, then the impedance interaction can be expressed as:

$$
T_{m}=\frac{G_{I N V}(s)}{G_{D A B}(s)}
$$

where $G_{I N V}(s)$ and $G_{D A B}(s)$ are the power control transfer functional of DAB and inverter, as shown in Fig. 4 and Fig. 7. The phase shift of $G_{I N V}(s)$ and $G_{D A B}(s)$ are both 90 degree at the low frequency part, then within this area $T_{m}$ will not introduce phase shift in the cascaded system.

For the feed forward control, when power reference stays the same, the load converter works in constant power mode, then it behaves as negative input impedance [36], with the phase shift of -180 degree. Under voltage control, the DAB converter has a 90 degree shift in its output impedance [20] in low frequency. So the $T_{m}$ will introduce a phase shift of $270(-90)$ degree, and the phase shift decreases the cascaded converter phase margin [37]. So the proposed control can improve the stability of the DABCI.

\section{SimUlation AND EXPERIMENT REsUlts}

\section{A. Simulation Results}

An interface converter prototype was built and simulated in PLECS to test the control strategy. Simulation parameters are shown in Table 1. The conventional control and feed forward control methods are also simulated for a comparison with the proposed one. The compared control methods are based on the same voltage controller and inside power (current) controller.

Fig. 23 shows the simulation results when the DAB controls power output and the inverter maintains DC-link voltage. As shown, when the power flow changes between $+5 \mathrm{~kW}$ and $5 \mathrm{~kW}$, the DC voltage fluctuates with a magnitude of $354 \mathrm{~V}$ from peak to peak, and takes 0.055 s to recover stable at $800 \mathrm{~V}$.

Fig. 24 shows the results when DAB maintains DC-link voltage, and inverter controls the power output.

TABLE 1

SIMULATION PARAMETERS FOR BIDIRECTIONAL INTERFACE CONVERTER

\begin{tabular}{cc}
\hline \hline Parameter & Value \\
\hline$V_{1}$ & $400 \mathrm{~V}$ \\
$\mathrm{~V}_{d c}$ & $800 \mathrm{~V}$ \\
$\mathrm{~V}_{\text {ACbus }}($ Phase to natural) & $311 \mathrm{~V}$ \\
$C$ & $3 m \mathrm{H}$ \\
$L_{1}$ & $100 \mathrm{uF}$ \\
\hline \hline
\end{tabular}

As shown in Fig. 24, under the same condition, the DC-link voltage fluctuation is $205 \mathrm{~V}$ from peak to peak, which is smaller than $354 \mathrm{~V}$ in Fig. 23. The DC voltage recovering time is $0.038 \mathrm{~s}$, faster than $0.055 \mathrm{~s}$ in Fig. 23. As mentioned before, DAB is faster than the inverter, so when inverter maintains DC voltage, it can not follow the power controlling converter rapidly, so the DC-link voltage fluctuation is enlarged during transitions.

Fig. 25 is the simulation result of the proposed control. As shown, when the power reference changes between $+5 \mathrm{~kW}$ and $-5 \mathrm{~kW}$, the DC-link voltage fluctuation is $115 \mathrm{~V}$, much smaller than previous $354 \mathrm{~V}$ and $205 \mathrm{~V}$ in Fig. 23 and Fig. 24, and the recovering time is $0.012 \mathrm{~s}$, also shorter than the previous cases. So when the DAB and inverter both regulate the DC-link voltage and power, the voltage fluctuations under power references variations can be better suppressed.

Fig. 26 is the comparison between the feed forward control and the proposed control. Before the vertical dash line, the system is with feed forward control, and after the dash line is the proposed control.

As shown in Fig. 26 (a), under square power reference, the fluctuation of DC-link voltage in the feed forward control is $132 \mathrm{~V}$, while in the proposed control the fluctuations is $115 \mathrm{~V}$ and steady state has less oscillation. In Fig. 26 (b), the power 
reference is sinusoidal with the frequency of $16 \mathrm{~Hz}$ and amplitude of 5000W. In the feed-forward control, the amplitude of voltage fluctuation is $60 \mathrm{~V}$; while in the proposed control, it is $38 \mathrm{~V}$. In feed-forward control, compared with the reference wave, the power output of DAB and inverter has

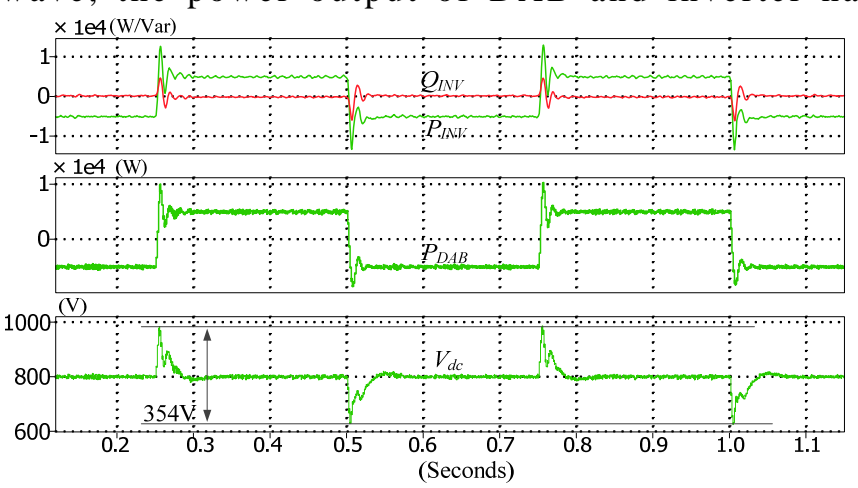

Fig. 23 DAB controls power output and inverter maintains DC voltage
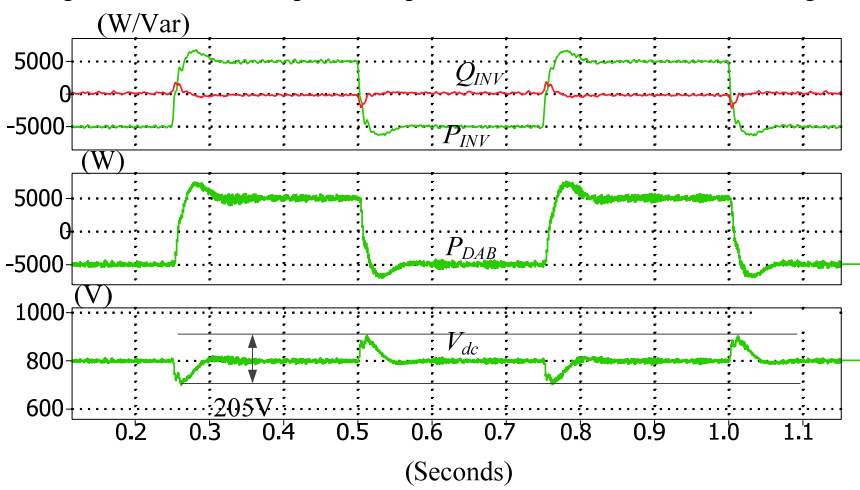

Fig. 24 DAB maintains DC voltage and inverter control power output

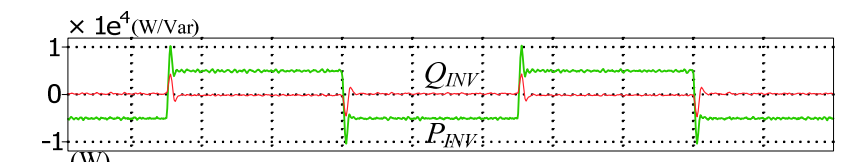

$-1+\ldots$.
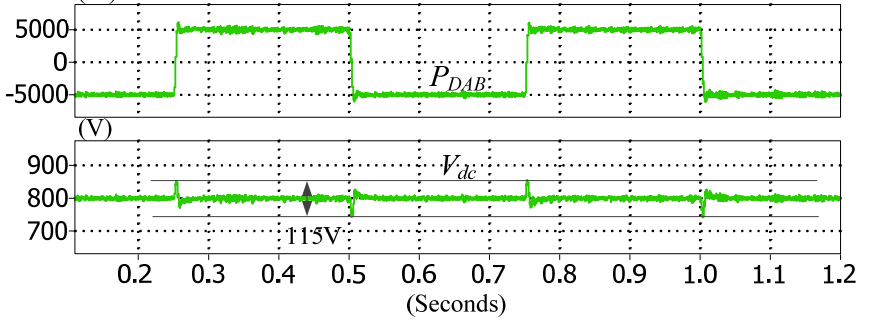

Fig. 25 Active power and DC voltage coordinative control for the cascaded system

TABLE 2

SiMULATION RESUltS AND MODELING STEP RESPONSE COMPARISON

\begin{tabular}{ccc}
\hline \hline Control method & Value & Simulation results \\
\hline Conventional control & $198 \mathrm{~V}$ & $205 \mathrm{~V}$ \\
Feed forward control & $136 \mathrm{~V}$ & $132 \mathrm{~V}$ \\
Proposed coordinative & $74 \mathrm{~V}$ & $115 \mathrm{~V}$ \\
control & \\
\hline \hline
\end{tabular}

apparent phase and amplitude error, while in the proposed control, DAB and inverter power output error are much less.

In Fig. 26 (c), the grid voltage has sag (0.2pu) at $0.25 \mathrm{~s}$ and $0.5 \mathrm{~s}$. In feed forward control, the voltage fluctuation is $65 \mathrm{~V}$; while in the proposed control, it is $49 \mathrm{~V}$. So the proposed control can damp the interference more effectively than the feed- forward control, and improve the performance of both the DClink voltage and the power output.

Table 2 is the comparison of simulation results with the modeling step response in Fig 19. The relevant trends of DClink voltage fluctuation are similar with each other, which can support the analysis.

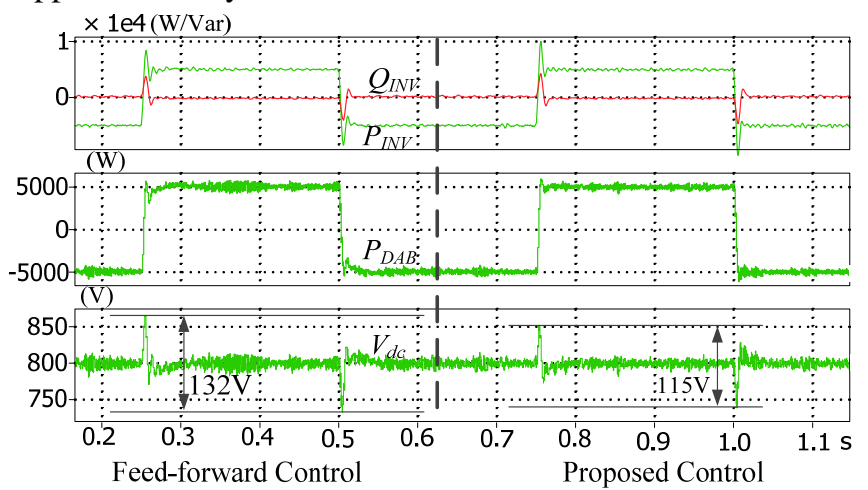

(a)Simulation results in the square reference wave

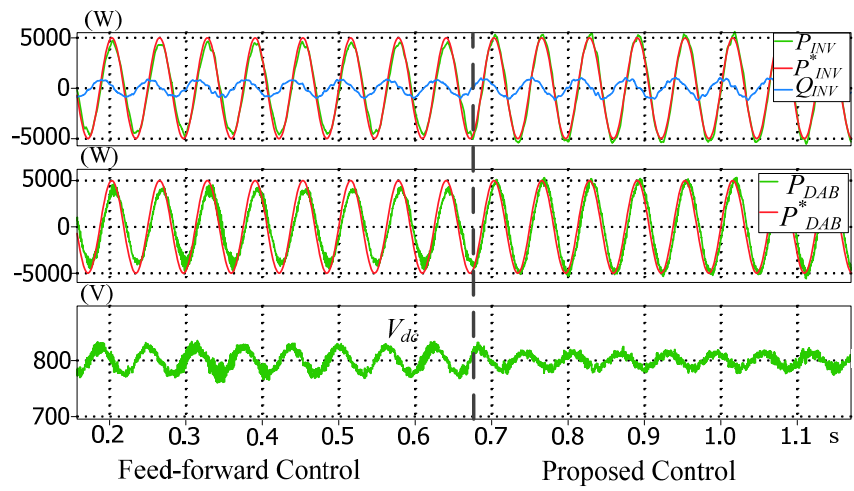

(b)Simulation results in the sinusoidal reference wave

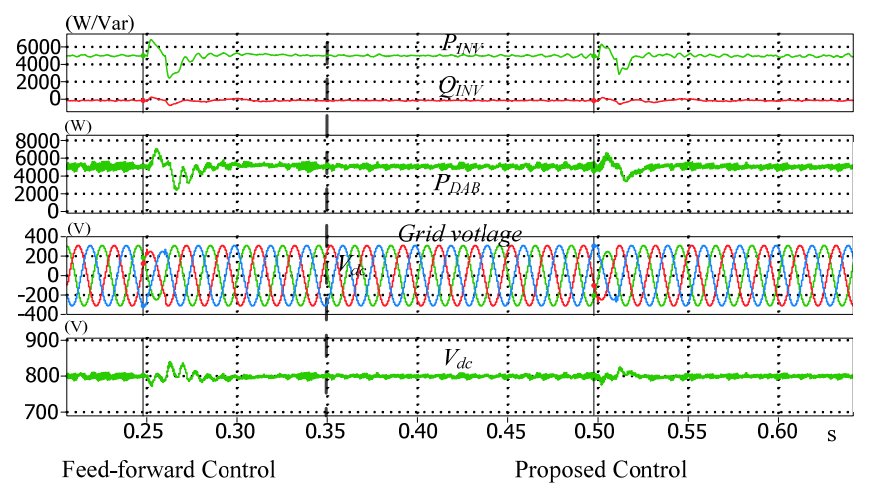

(c)Simulation results in grid voltage sag

Fig. 26 Feed forward control with active power and DC voltage coordinative control

\section{B. Experimental Results}

A scaled-down $800 \mathrm{~W}$ laboratory prototype has been built, and the topology is shown in Fig. 27. The parameters are shown in Table 3. The inverter is connected with grid through a transformer.

The transformer core of the DAB converter is ETD59, and the voltage and current wave forms of the primary side and secondary side are shown in Fig. 28 (a). Primary side voltage is $130 \mathrm{~V}$ square wave, and secondary side voltage is $400 \mathrm{~V}$ square 
wave. Fig. 28 (b) is the current step response of the inverter, and the output power varied from 0 to $1 \mathrm{~kW}$.

The experiment scenario is to change the active power reference between $400 \mathrm{~W}$ and $-400 \mathrm{~W}$ with the period of $0.4 \mathrm{~s}$, and maintain reactive power at 0 Var. Conventional control employs the DAB to maintain DC voltage, and inverter

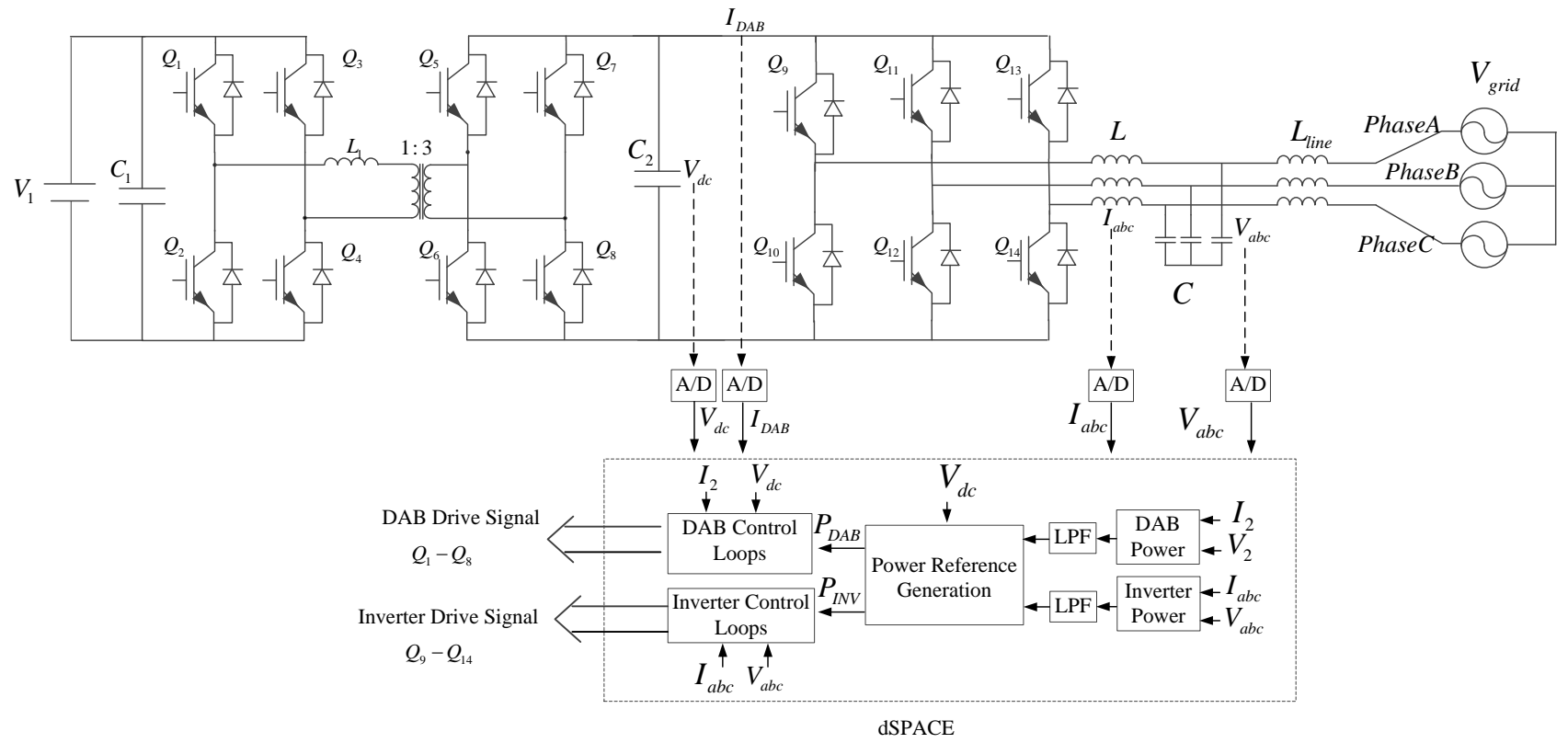

Fig. 27 Experiment setup of the cascaded interface converter

power output. The feed-forward control introduces a reference feed forward signal to DAB.

Fig. 29 is the experiment results of the power output and DC-link voltage. The power waves are captured from the DA output block DS2101 of dSPACE.

As shown in Fig. 29 (a), before 0.1s, the system is under conventional control, and when power output changes, the DClink voltage fluctuation is $84 \mathrm{~V}$, and needs 0.115 s to recover. After $0.1 \mathrm{~s}$, the operation is switched to the proposed control. Under the same control parameters, the DC-link voltage fluctuation is $28 \mathrm{~V}$, needs $0.04 \mathrm{~s}$ to recover. And also the dynamic response of power output are faster than the conventional.

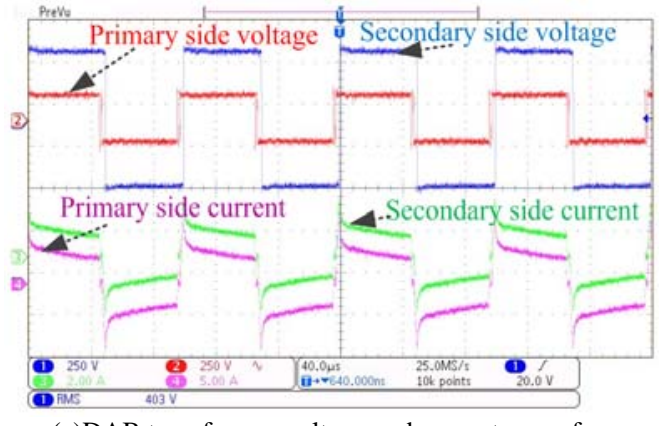

(a)DAB transformer voltage and current wave forms

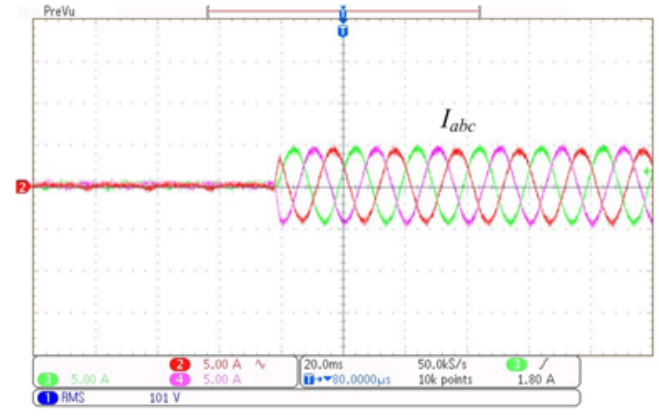

(b) Inverter current waveforms under step response

Fig. 28 Current wave forms under conventional control method TABLE 3

EXPERIMENTAL PARAMETERS FOR BIDIRECTIONAL INTERFACE CONVERTER

\begin{tabular}{cc}
\hline \hline Parameter & Value \\
\hline DC voltage $\left(V_{1}\right)$ & $130 \mathrm{~V}$ \\
Middle DC voltage $\left(V_{2}\right)$ & $400 \mathrm{~V}$ \\
Ratio for DAB Transformer & $1: 3$ \\
Transformer leakage inductor & $200 \mathrm{uH}$ \\
Middle DC Capacitors & $300 \mathrm{uF}$ \\
AC voltage $\left(V_{3}\right)$ & $150 \mathrm{~V}$ \\
Inductor of LC filter & $3 \mathrm{mH}$ \\
Switching Frequency & $3 \mathrm{mH}$ \\
DAB Parameter & $10 \mathrm{kHz}$ \\
DC voltage $\left(V_{1}\right)$ & Value \\
Middle DC voltage $\left(V_{2}\right)$ & $130 \mathrm{~V}$ \\
Ratio for DAB Transformer & $400 \mathrm{~V}$ \\
Transformer leakage inductor & $1: 3$ \\
Middle DC Capacitors & $200 \mathrm{uH}$ \\
\hline \hline
\end{tabular}

As shown in Fig. 29 (b), before $0.1 \mathrm{~s}$, the system is under feed forward control, and DC-link voltage fluctuations are $40 \mathrm{~V}$, and recovering time is $0.08 \mathrm{~s}$. After $0.1 \mathrm{~s}$, the operation is 
switched to the proposed control. DC-link voltage fluctuations are $30 \mathrm{~V}$, and DC-link voltage recovering time is

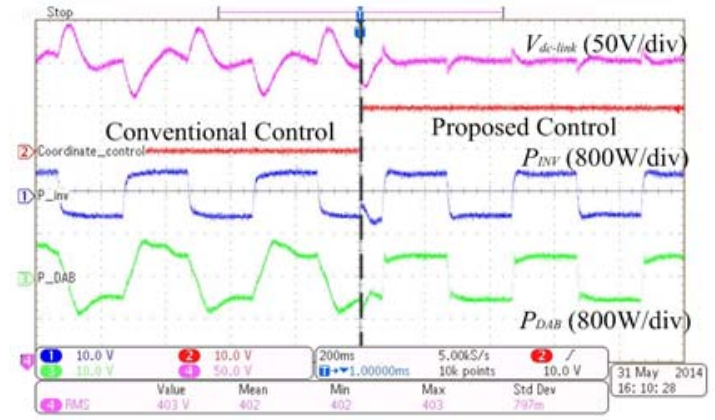

(a) Switching from conventional control to proposed control

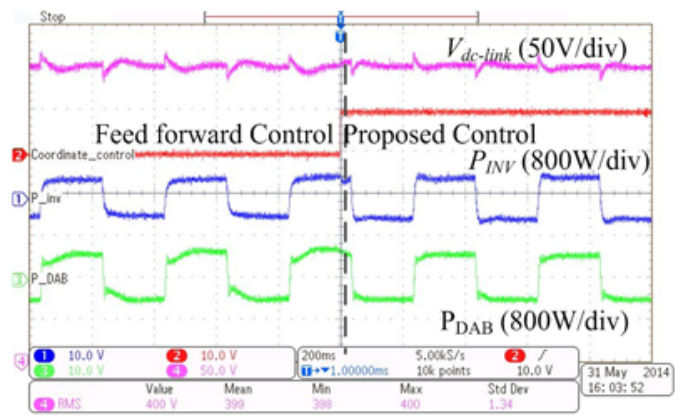

(b) Switching from feed forward control to proposed control

Fig. 29 Experiment results of the power output and DC-link voltage

0.04s. So the proposed control can maintain DC-link voltage better, with smaller voltage fluctuations and faster recovering speed. And the power outputs are faster in proposed control than feed forward control.

Fig. 30 is the experiment result of DAB output current, voltage and the active power. As shown in Fig. 30 (a), after switching from conventional control to the proposed coordinative control, dynamic response of DAB output current becomes much faster, so is the power output.

As shown in Fig. 30 (b), after switching from feed forward control to the proposed coordinative control, dynamic response of $\mathrm{DAB}$ output current becomes faster, because the sharing control makes the DC-link voltage more stable.

Fig. 31 is the experiment results of three phase inverter output current, and the DC-link voltage

As shown in Fig. 31 (a), after switching from conventional control to the proposed coordinative control, inverter maintains the DC-link voltage at the instant time.

In Fig. 31 (b), after switching from feed forward control to the proposed control, dynamic response of inverter output current behaves faster to maintain DC-link voltage, because of the sharing control of DC-link voltage.

Fig. 32(a) shows the comparison between the proposed control and the feed forward control, where the power reference is sinusoidal with the frequency of $1.8 \mathrm{~Hz}$ and the amplitude of 300 W. From Fig. 32(a), it can be observed that the DC-link voltage has some oscillation in the feed forward control, because the power of the two converters (DAB and inverter) cannot match each other well. After the proposed control is used, the power of the two converters (DAB and inverter) can be more closely followed by each other and the dc-link voltage oscillation can be effectively damped. It shows the good agreement with the theoretical analysis in Section III, where the proposed control can control the DC-link voltage more stable with better stability.

Fig. 32(b) shows the performance of the proposed control and the feed forward control under grid voltage dip, where the grid voltage drops to 0.5 p.u. and lasts for $0.02 \mathrm{~s}$. It can be seen that the proposed control can provide a more stable DC-link voltage in comparison with the feed forward control. The grid voltage is emulated by a programmable AC source power and it has less inductance than the transformer, which means damping in the AC net becomes much smaller, so the DC-link voltage has more oscillation than the cases with transformer, but under the same condition, the DC-link voltage in the proposed control is more stable than feed forward control.

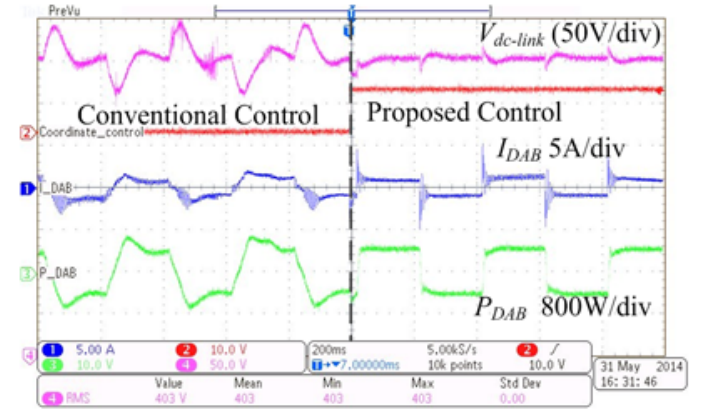

(a)Switching from conventional control to the proposed control

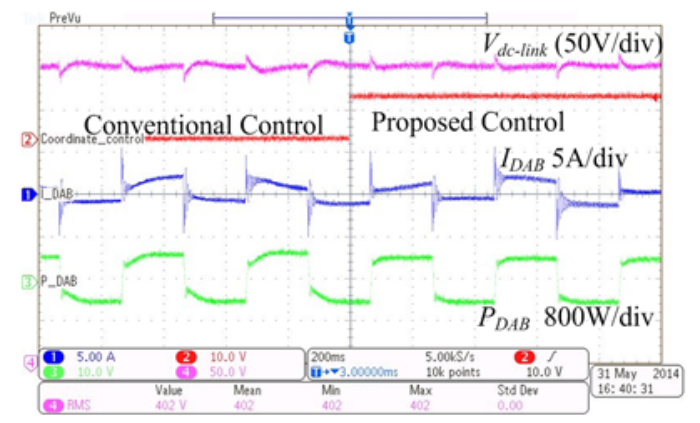

(b)Switching from feed forward control to the proposed control

Fig. 30 Experiment results of DAB converter output current, active power and DC-link voltage

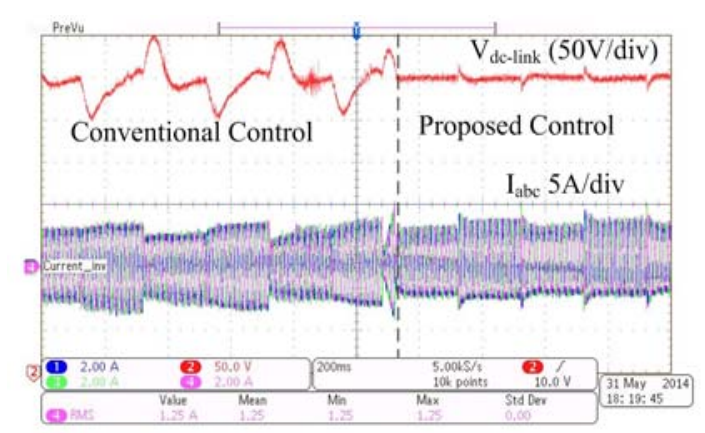

(a) Switching from conventional control to the proposed control 


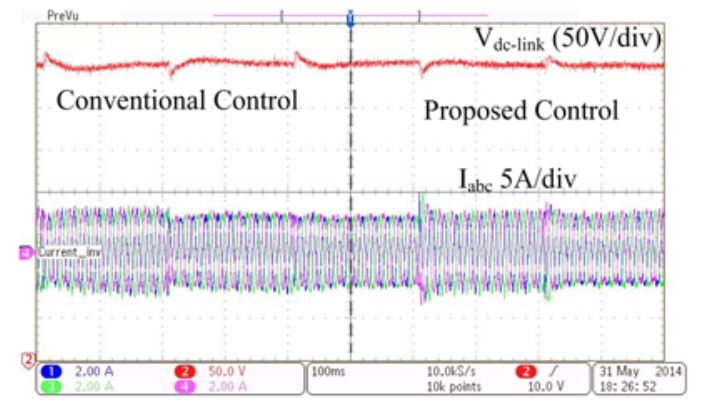

(b)Switching from feed forward control to the proposed control

Fig. 31 Experiment results of inverter output current and DC-link voltage

As shown in Fig. 30, Fig. 31 during the transitions of power reference variations, the proposed control can maintain the DClink voltage at the instant time by changing its sub-converters' output current, which makes the DC-link voltage more constant during the transitions.

The energy $(E)$ stored on the DC-link capacitor can be calculated as

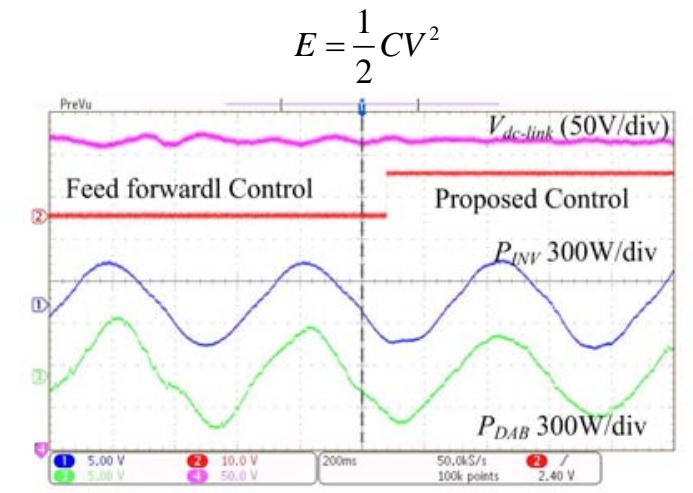

(a)With sinusoidal power reference wave

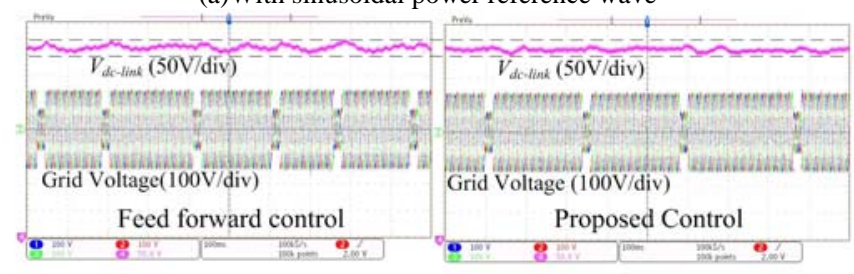

(b) Feed-forward control and the proposed control under voltage sag Figure 32 Experiment results of feed forward control and the proposed control

where $C=300 \mathrm{uF}, V=400 \mathrm{~V}$; So $E=24 \mathrm{~W}$, so compared with the transferred power, it is very small. With a better controlled DC-link voltage, the dynamic response of the whole converter becomes faster.

\section{CONCLUSIONS}

This paper proposes a DC-link voltage and active power coordinative control method for a cascaded DC-AC interface converter. The coordinative control makes the inverter and $\mathrm{DAB}$ to share the tasks of maintaining DC-link voltage and controlling power output. The system models have been derived and the dynamic response with stability have been analyzed, which shows that the proposed control method can reduce the DC-link voltage fluctuations, and provide more effectively damping with better stability. Therefore, the required volume of DC-link capacitors can be reduced, and the stress on the semiconductors are also reduced. The results have been validated by the simulation and experiment results.

\section{ACKNOWLEDGEMENTS}

The authors would like to thank, also to thank the China Scholarship Council for a scholarship. Further, Mr. Kiwoo Park, Department of Energy Technology, Aalborg University, is thanked for his help on building the experiment setup.

\section{APPENDIX}

TABLE 4

EXPERIMENTAL PARAMETERS FOR BIDIRECTIONAL INTERFACE CONVERTER

\begin{tabular}{cc}
\hline \hline Parameter & Value \\
\hline DAB power loop $K_{P-D A B}$ & 0.00001 \\
DAB power loop $K_{i-D A B}$ & 0.0105 \\
DAB Switching frequency & $10 \mathrm{kHz}$ \\
DAB Control bandwidth & $1884 \mathrm{rad} / \mathrm{s}$ \\
Inverter Current Loop $K_{P-I N V}$ & 2.5 \\
Inverter Current Loop $K_{i-I N V}$ & 500 \\
Switching frequency & $10 \mathrm{k} \mathrm{Hz}$ \\
Inverter Control bandwidth & $1570 \mathrm{rad} / \mathrm{s}$ \\
DC-link Voltage Controller $K_{P}$ & 40 \\
DC-link Voltage Controller $K_{i}$ & 1000 \\
\hline \hline
\end{tabular}

\section{REFERENCES}

[1] R. Lasseter:, "Mircrogrids," in Proc. IEEE Power Eng. Soc. Winter Meet, 2002, pp. 305-308.

[2] F. Katiraei and M. R. Iravani, "Power management strategies for microgrid with multiple distributed generation units," IEEE Transactions on. Power Systemt, vol. 21, no. 4, pp 1821-1831, Nov. 2006.

[3] Josep M. Guerrero, Jose Matas, Luis Garcia de Vicuna, Miguel Castilla, Jaume Miret. "Decentralized Control for Parallel Operation of Distributed Generation Inverter Using Resistive Output Impedance.” IEEE Transactions on Industrial electronics, Vol.54, NO.2April, 2007.

[4] P. C. Loh, and D. Li, Y. K. Chai, and F. Blaabjerg, "Hybrid AC-DC Microgrids With Energy Storages and Progressive Energy Flow Tuning ," IEEE Trans. Power Electroncis, vol. 28, no. 4,pp. 1533-1542, Apr.2013.

[5] R.T. Naayagi, A.J. Forsyth, R. Shuttleworth, "Bidirectional control of a dual active bridge DC-DC converter for aerospace applications," IET Power Electrons, VOL. 5, Iss. 7, 2012, pp. 1104-1118.

[6] C. Cecati, A. Dell'Aquila, M. Liserre, "A Novel Three-Phase SingleStage Distributed Power Inverter". IEEE Transactions on Power Electronics, Vol. 19, NO. 15, SEPTEMBER 2004.

[7] Y. H. Change, "Design and Analysis of Power-CMOS-Gate-Based Switched-Capacitor Boost DC-AC Inverter IEEE Transactions on Circuits and System-1, Regular Papers, Vol. 51, NO. 10, OCTOBER 2004.

[8] K. You, M. F. Rahman, "A Martrix-Z-Source Converter With AC-DC Bidirectional Power Flow for an Integrated Starter Alternator System”. IEEE Transactions on Industry Applications, Vol. 45, NO. 1, JANUARY/FEBRUARY 2009.

[9] M. Jiang, V. G. Agelidis, "A Minimum Power-Processing-Stage FuelCell Energy System Based on a Boost-Inverter Wth a Bidiectional Backup Battery Storage”, IEEE Transactions on Power Electronics, Vol. 26, NO. 5. MAY 2011.

[10] Leandro Roggia, Luciano Schuch, Jos'e Eduardo Baggio, Cassiano Rech, Jos'e Renes Pinheiro, "Integrated Full-Bridge-Forward DC-DC Converter for a Residential Microgrid Application,” IEEE Transactions on Power Electronics, Vol. 28, NO. 4, APRIL 2013.

[11] Hua Bai, Chris Mi, "Eliminate Reactive Power and Increase System Efficiency of Isolated Bidirectional Dual-Active-Bridge DC-DC Converters Using Novel Dual-Phase-Shift Control,” IEEE Transactions on Power Electronics, VOL. 23, NO. 6, NOVEMBER 2008.

[12] Dinesh Segaran, Donald Grahame Holmes, Brendan Peter McGrath, "Enhanced Load Step Response for a Bidirectional DC-DC Converter," 
IEEE Transactions on Power Electronics, VOL. 28, NO. 1, JANUARY 2013.

[13] Florian Krisme, Johann W. Kolar, "Efficiency-Optimized High-Current Dual Active Bridge Converter for Automotive Applications,” IEEE Transactions on Power Electronics, VOL. 59, NO. 7, JULY 2012.

[14] Hengsi Qin, Jonathan W. Kimball, "Solid State Transformer Architecture Using AC-AC Dual Active Bridge Converter,” IEEE Transactions early access.

[15] Md. Rabiul Islam, Youguang Guo, Jianguo Zhu, “A High-Frequency Link Multilevel Cascaded Medium-Voltage Converter for Direct Grid Integration of Renewable Energy Systems," IEEE Trans on Power Electronics, VOL. 29, NO. 8, AUGUST 2014

[16] B. Wang, G. Venkataramanan, "Dynamic Voltage Restorer Utilizing a Matrix Converter and Flywheel Energy Storage," IEEE Transactions on Industry Application, VOL. 45, NO. 1, January, 2009.

[17] D. Dong, F. Luo, X. Zhang, D. Boroyevich, P. Mattavelli, “Grid-Interface Bidrectional Converter for Residential DC Distribution Systems-Part 2: AC and DC Interface Design With Passive Components Minimization,” IEEE Transactions on Power Electronics, Vol. 28, No. 4, April. 2013.

[18] D. Dong, F. Luo, X. Zhang, D. Boroyevich, P. Mattavelli, “Grid-Interface Bidrectional Converter for Residential DC Distribution Systems-Part 1: High-Density Two-Stage Topologym,” IEEE Transactions on Power Electronics, Vol. 28, No. 4, April 2013.

[19] T. Zhao, G. Wang, S. Bhattacharya, A. Q. Huang, "Voltage and Power Balance Control for a Cascaded H-Bridge Converter-Based Solid-State Transformer”, IEEE Transactions on Power Electronics, Vol. 28, NO. 4, April 2013.

[20] Harish Krishnamurthy, Raga Ayyanar, "Stabitlity Analysis of Cascaded Converters for Bidirectional Power Flow Application”, Telecommunications Energy Conference. San Diego, CA 14-18 Sept, 2008.

[21] Harish K. Krishnamurthy, Raja Ayyanar, "Building Block Converter Module for Universal (AC-DC, DC-AC, DC-DC) Fully Modular Power Conversion Architecture," Power Electronics Specialists Conference 2007, Orlando, FL, 17-21 June 2007.

[22] Hirofumi Akagi, Ryohei Kitada, "Control and Design of a Modular Multilevel Cascade BTB System Using Bidirectional Isolated DC/DC Converters", IEEE Transactions on Power Electronics, Vol.26, No. 9, Septemeber.2011.

[23] Hua Bai, Chris Mi, “Eliminate Reactive Power and Increase System Efficiency of Isolated Bidirectional Dual-Active-Bridge DC-DC Converters Using Novel Dual-Phase-Shift Control, ” IEEE Transaction on Power Electronics, VOl.23, NO.6, Nov 2008.

[24] S. R. Sanders, J. M. Noworolski, X. Z. Liu, and G. C. Verghese, "Generalized averaging method for power conversion circuits," IEEE Transactions on Power Electron, Vol. 6, No. 2, pp. 251-259, 1991

[25] Hengsi Qin, Jonathan W. Kimball, "Generalized Average Modeling of Dual Active Bridge DC-DC Converter”, IEEE Transactions on Power Elelectronics, Vol. 27, NO. 44, pp. 2078-2084, APRIL 2012,

[26] Hengsi Qin, Jonathan W. Kimball, “Closed-loop Control of DC-DC Dual Active Bridge Converters Driving Single-Phase Inverters”, IEEE early Access.

[27] Md Rasheduzzaman, Jacob A. Mueller, Jonathan W. Kimball, "An Accurate Small-Signal Model of Inverter-Dominated Islanded Microgrids Using dq Reference Frame,” IEEE Journal of Emerging and Selected Topics in Power Electronics, , Vol. 2, NO. 4, Dec 2014.

[28] X. Sun, Y. Tian, Z. Chen, "Adaptive decoupled power control method for inverter connected DG,” I E T Renewable Power Generation, Sep 2013.

[29] Mohammad Monfared, Saeed Golestan, Josep M. Guerrero , ”Analysis, Design, and Experimental Verification of a Synchronous Reference Frame Voltage Control for Single-Phase Inverters”, IEEE Transactions on Industrial Electronics, VOL. 61, NO. 1, JANUARY 2014.

[30] Ahmadi, R. ; Electr. \& Comput. Eng. Dept., Missouri Univ. of Sci. \& Technol., Rolla, MO, USA ; Ferdowsi, M,” Controller design method for a cascaded converter system comprised of two DC-DC converters considering the effects of mutual interactions," Applied Power Electronics Conference and Exposition (APEC), 2012 ,5-9 Feb. pp:1838 $-1844$.

[31] Xin Zhang, Xinbo Ruan, Hyok Kim, Chi K.Tse, “Adaptive Active Capacitor Converter for Improving Stability of Cascaded DC Power Supply System," IEEE Transactions on Power Electronics, Vol. 28, No. 4, April 2013.
[32] B. H. Cho, B. Choi, "Analysis and design of multi-stage distributed power systems," in Proc. Int. Telecommun. Energy Conference. Kyoto, Japan. Nov. 1991.

[33] From the website of Wiki, input impedance, http://en.wikipedia.org/wiki/Input_impedance.

[34] From the webite of Wiki, output impedance, http://en.wikipedia.org/wiki/Output_impedance.

[35] R.D. Middlebrook, "Input filter considerations in design and application of switching regulators," in Proc. IEEE IAS. 1979, pp 366-382.

[36] Ali Ema, Alireza Khaligh, Claudio H. Ritetta, Geoffrey A. Williamson, "Constant Power Loads and Negative Impedance Instability in Automotive System:Definition, Modeling, Stability, and Control of Power Electronic Converters and Motor Drives," IEEE Transactions on Vehicular Technology, Vol. 55, NO. 4, July, 2006.

[37] Carl M. Wildrick, Fred C. Lee, Bo H. Cho, Byungcho Choi, “A Method of Defining the Load Impedance Specification for A Stable Distributed Power System,” IEEE Transactions on Power Electronics, Vol. 10, NO. 3. May, 1995.

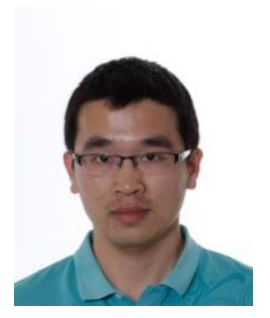

Yanjun Tian (S'14) received the B.Sc. and M.Sc. degree in electrical engineering from the Yanshan University, Qinhuangdao, China in 2009 and 2012, respectively. He is currently working toward the $\mathrm{PhD}$ degree in the department of Energy Technology, Aalborg University Denmark.

His research interest are distributed generation and active distribution network control, focusing on the impedance interaction, cascaded converter control and the parallel connected converter control.

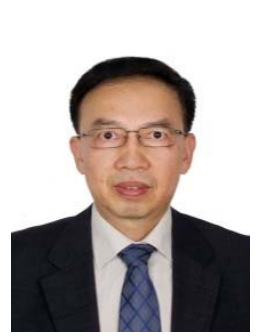

Zhe Chen (M'95-SM'98) received the B.Eng. and M.Sc. degrees from Northeast China Institute of Electric Power Engineering, Jilin City, China, and the Ph.D. degree from University of Durham, U.K.

He is a full Professor with the Department of Energy Technology, Aalborg University, Denmark. He is the leader of Wind Power System Research program at the Department of Energy Technology, Aalborg University and the Danish Principle Investigator for Wind Energy of Sino-Danish Centre for Education and Research.His research areas are power systems, power electronics and electric machines; and his main current research interests are wind energy and modern power systems. He has led many research projects and has more than 400 publications in his technical field.

Dr Chen is an Editor of the IEEE Transactions on Power Systems, an Associate Editor of the IEEE Transactions on Power Electronics, a Fellow of the Institution of Engineering and Technology (London, U.K.), and a Chartered Engineer in the U.K.

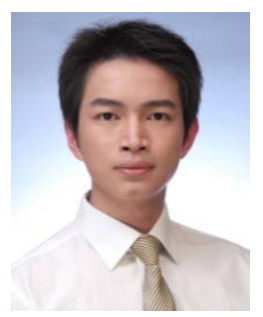

Fujin Deng (S'10, M'13) received the B.Eng. degree in electrical engineering from China University of Mining and Technology, Jiangsu, China, in 2005, the M.Sc. Degree in electrical engineering from Shanghai Jiao Tong University, Shanghai, China, in 2008, and the Ph.D. degree in energy technology from the Department of Energy Technology, Aalborg University, Aalborg, Denmark, in 2012.Currently, he is a Postdoctoral Researcher in the Department of Energy Technology, Aalborg University, Aalborg, Denmark.

His main research interests include wind power generation, multilevel converters, DC grid, high-voltage direct-current (HVDC) technology, and offshore wind farm-power systems dynamics. 
Yanting Hu (M’01, SM'08) received the B.Eng. and M.Sc. degrees from Northeast China Institute of Electric Power Engineering, China, and Ph.D. degree from De Montfort University, U.K.

Dr. Hu is with Department of Engineering and Physics Science, Glyndwr University, UK. She has been leading the EE Eng. Master programs, and a PhD students' study director of the Energy and Smart Grid research group.

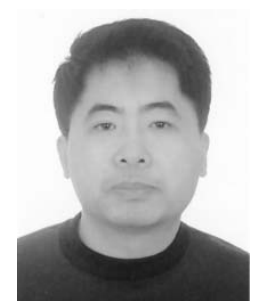

Xiaofeng Sun (M'13) received the B.S. degree in electrical engineering from Northeast Heavy Machinery Institute, Heilongjiang, China, in 1993, and the M.S. and Ph.D. degrees in power electronics from Yanshan University, Qinhuangdao, China, in 1999 and 2005, respectively.

From 2003 to 2007, he was an Associate Professor with the Department of Electrical Engineering, Yanshan University, where he has been a Professor since 2008. He is currently the Director of Key Laboratory of Power Electronics for Energy Conservation \& Motor Drive of Hebei Province, China. His current research interests include dc-dc converters, multiport converters, hybrid electric vehicles (HEVs), microgrids and power quality control. He has authored and coauthored more than 70 transactions and conference papers. He is the holder of four granted patents of inventions. 